\title{
Opioids in chronic noncancer pain: More faces from the crowd
}

\author{
C Peter N Watson MD FRCPC
}

CPN Watson. Opioids in chronic noncancer pain: More faces from the crowd. Pain Res Manage 2012;17(4):263-275.

BACKGROUND: The use of opioids for chronic noncancer pain (CNCP) remains very controversial. There are several randomized controlled trials, mostly in neuropathic pain, reporting efficacy and safety in the short term, but more long-term data are needed. Randomized controlled trials may be limited in providing data about the patients who benefit from often high-dose opioids over the long term. The present article provides details of these patients and adds to a previous case series. METHODS: The present article contains 17 case reports of $11 \mathrm{CNCP}$ conditions (followed to 2011) selected to illustrate specific issues from a survey of 84 patients with intractable CNCP treated with opioids and followed every three months for a median of 11 years. The previous published survey of this group reported outcomes of pain severity, adverse effects, pain relief, satisfaction, mood, problematic opioid use, tolerance, physical dependency, functional status, health-related quality of life (HRQL), immune status and sexual function. The outcome measures for that study included a numerical rating scale for pain, the Hospital Anxiety and Depression Scale, the Brief Pain Inventory Interference Scale, the Pain Disability Index and, for HRQL, the Short-Form Health Survey 12 version 2. Most patients in the total sample reported $50 \%$ or greater relief and a moderate improvement in disability. Scores for functional status and HRQL were not severely affected. Problematic use, tolerance and serious adverse effects, including constipation, were not major issues. These selected patient reports were chosen, not to illustrate optimal results, but rather important aspects of the diagnoses, opioids and doses, the paucity of intolerable adverse effects, particular issues (concurrent addiction history, bipolar disorder and combination therapy), disease-specific and other outcomes and duration of follow-up with complex pain problems.

RESULTS: Opioids were found to be safe and useful in the long term for these particular patients, as well as in the larger group from which they originated.

INTERPRETATION: These 17 reports of patients with intractable $\mathrm{CNCP}$ treated with opioids with some success over many years puts a face on more of the participants in the larger survey of 84 subjects, suggesting that this approach is effective and safe for some patients over many years.

Key Words: Chronic noncancer pain; Long-term safety and efficacy; Opioids

$\mathrm{O}$ verall, in the clinical setting, a picture is seen of diminishing efficacy with chronic use (of opioids) and ... it is patients who escalate to high doses who seem to develop refractoriness (1).

The use of NSAIDS, physiotherapy and cognitive behaviour therapy might provide as much relief as opioids (2).

There were some wise men

To learning much inclined

Who went to see the elephant

Though all of them were blind,

That each by observation

Might satisfy his mind.

Adapted from the folk tale: The Blind Men and the Elephant

\section{Les opioïdes pour soigner la douleur chronique d'origine non cancéreuse : plus de visages émergent de la foule}

HISTORIQUE : Le recours aux opioïdes pour soigner la douleur chronique d'origine non cancéreuse (DCONC) demeure très controversé. Plusieurs essais aléatoires et contrôlés, portant surtout sur la douleur neuropathique, font foi d'une efficacité et d'une innocuité à court terme, mais plus de données à long terme s'imposent. Les essais aléatoires et contrôlés comportent peut-être des limites pour fournir des données sur les patients qui profitent des doses élevées d'opioïdes fréquentes à long terme. Le présent article fournit de l'information détaillée sur ces patients et enrichit une série de cas antérieurs.

MÉTHODOLOGIE : Le présent article contient 17 rapports de cas au sujet de 11 troubles de DCONC (suivis jusqu'en 2011) sélectionnés pour illustrer des problèmes précis d'après une enquête sur 84 patients souffrant de DCONC réfractaire qui avaient été traités aux opioïdes et suivis tous les trois mois pendant une médiane de 11 ans. L'enquête déjà publiée sur ce groupe rendait compte d'issues en matière de gravité de la douleur, d'effets indésirables, de soulagement de la douleur, de satisfaction, d'humeur, d'utilisation problématique des opioïdes, de tolérance, de dépendance physique, d'état fonctionnel, de qualité de vie liée à la santé (QVLS), d'état immunitaire et de fonction sexuelle. Les mesures d'issue de cette étude incluaient une échelle d'évaluation numérique de la douleur, l'échelle d'anxiété et de dépression à l'hôpital, l'échelle d'interférence du bref inventaire de la douleur, l'indice d'invalidité causée par la douleur et, pour la QVLS, le sondage court en 12 points sur la santé, version 2. La plupart des patients de l'ensemble de l'échantillon ont déclaré un soulagement de $50 \%$ ou plus et une amélioration modérée de l'invalidité. Les indices d'état fonctionnel et de QVLS n'étaient pas gravement touchés. Une utilisation problématique, la tolérance et de graves effets indésirables, y compris la constipation, ne représentaient pas des problèmes majeurs. Le rapport de ces patients sélectionnés a été retenu non pas pour démontrer des résultats optimaux, mais plutôt pour exposer des aspects importants des diagnostics, les opioïdes et les doses, le peu d'effets indésirables intolérables, des problèmes particuliers (toxicomanie concomitante, trouble bipolaire et thérapie d'association), des issues propres à la maladie et d'autres résultats ainsi que la durée du suivi en cas de problèmes de douleur complexes.

RÉSULTATS : Il a été établi que les opioïdes étaient sécuritaires et utiles à long terme pour ces patients, de même que pour le groupe plus important dont ceuxci étaient extraits.

INTERPRÉTATION : Ces 17 rapports de patients souffrant d'une DCONC réfractaire et qui avaient été traités aux opioïdes avec un certain succès pendant de nombreuses années mettent un visage sur plus de participants de l'enquête plus vaste sur 84 sujets et laissent croire que cette démarche est à la fois efficace et sécuritaire pendant de nombreuses années pour certains patients.

We must decide to what extent these two quotations surrounding the use of opioids are true for chronic noncancer pain $(\mathrm{CNCP})$ or whether these opinions reflect a particularly negative view that is not applicable to all patients, as in the folk tale of the visually challenged men and the elephant. There does, however, seem to be agreement among some of those embroiled in this great controversy that there is a void regarding long-term data and that at least some patients may be helped in this way if thoughtful care is taken (3).

Chronic pain is common in populations in North America and Europe. CNCP was reported by $29 \%$ of respondents in a Canadian survey (4). In Europe, a stable figure of $20 \%$ of the Danish population suffer mostly from CNCP (5-7) and, consistent with this, a recent study from Kansas (USA) reported a figure of $26 \%$ (8). These numbers are similar to a WHO figure of $20 \%$ of the world's population experiencing 


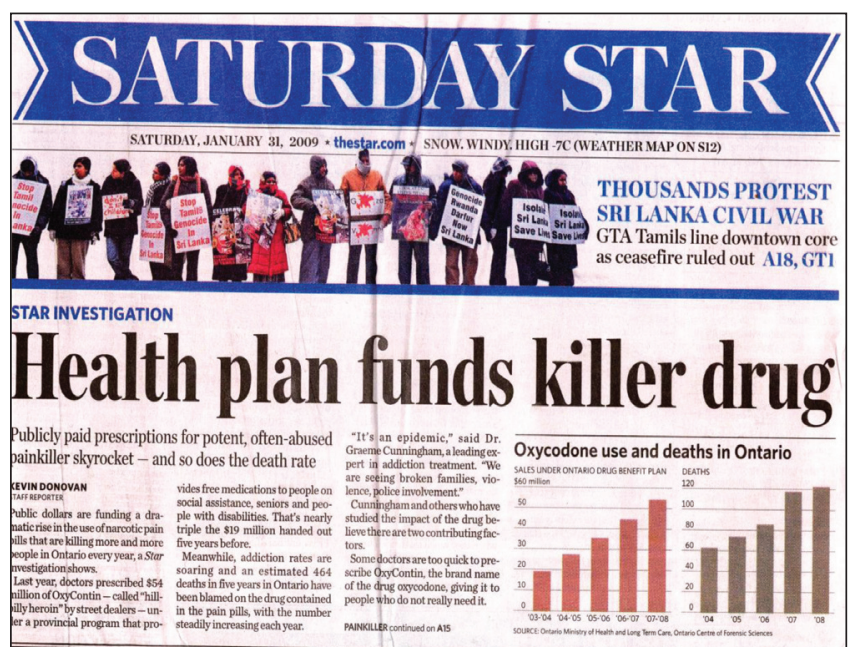

Figure 1) Newspaper headline from Toronto, Ontario, regarding longacting oxycodone

some degree of chronic pain (9). There has been an increase in the use of opioids for CNCP in Europe $(10,11)$ and in the United States $(10,12,13)$. Furthermore, a reported increase in the abuse of and deaths associated with opioids has also been documented $(12,13)$. The latter has been related to the daily dose used (14).

There is currently an impasse in the investigation of more effective drugs for CNCP. Randomized controlled trials (RCTs) churn out placebo-controlled studies of monotherapies of old and new drugs that are only moderately effective, even in the selected population of an RCT, but are of limited external validity and that may be useful to few patients in ordinary practice (15). Head-to-head RCTs of newer drugs (gabapentinoids, serotonin noradrenaline reuptake inhibitors antidepressants) versus older drugs (tricyclic antidepressants, opioids) are few, but combined with numbers needed to treat and harm figures, provide little or no consistent evidence of superiority or even equivalency of new versus older agents $(16,17)$. Because of this limitation in our therapeutic drug armamentarium as well as the lack of efficacy of nonpharmacological approaches for many patients, opioids, sometimes in high doses, may need to be considered for refractory patients.

Despite a number of RCTs of opioids in CNCP showing efficacy and safety in the short term (18-27), the long-term use of opioids for these conditions remains controversial in view of concerns about longterm efficacy and safety. Efficacy concerns include pain relief, tolerance, improvement in function and health-related quality of life (HRQL). Safety concerns include the risk of problematic use and diversion, increased pain sensitivity such as hyperalgesia with high doses, potential effects on the immune and endocrine systems, cognitive/affective changes and mortality from overdose (28-35). Minimal data regarding the long-term effects in CNCP patients treated with opioids are available. It is difficult to conduct an RCT over long periods of time, and data in this regard are both epidemiological $(5,7,36$ 38) and observational (39-44).

The current debate raging about the long-term efficacy and safety of opioids in CNCP may be likened to the story of the different opinions of the blind men about the elephant. In this tale, each individual has a different part of the beast in his hands and draws a different conclusion about its nature. Individuals could include those involved in pain treatment, addiction medicine specialists, clinical trialists, epidemiologists, the police, coroners, pharmacists, the television and print media (Figure 1), family physicians and the public (especially those who have lost loved ones to the ravages of addiction). An extrapolation of this tale may be to ponder that, even when the whole animal is correctly identified, the question remains as to whether it is a trainable Indian elephant, perhaps prone to an occasional rampage, or the completely unmanageable African species. If this is the Indian species, then the training and experience of the mahout (elephant driver) may be critical.
It is timely and of great importance that we document and put a face on the patients who benefit substantially, particularly in diseasespecific ways and only from these drugs, for long periods of time safely. The purpose of the present article is to add 17 patients with $11 \mathrm{CNCP}$ conditions on long-term, often high-dose, opioids to other cases (45) drawn from a case series (44).

\section{METHODS}

The present case series of 17 patients was selected and updated to 2011 from a group of 84 patients with intractable, daily, severe CNCP treated with opioids for at least one year, living in the community, followed regularly every three months and surveyed in detail between September 1 and December 31, 2007 (44). These patients were chosen, not because they responded best, but to illustrate the most common cause of CNCP (low back pain with and without neuropathic leg pain) and the most common conditions used in RCTs (postherpetic neuralgia and diabetic neuropathy). Uncommon causes of neuropathic pain (NP) (brachial plexus neuropathy, phantom pain, causalgia) and non-NP (arthritis, osteomyelitis, headache) are also represented. As well, the use of high and low doses of opioids and combination drug therapy with nonopioids is notable. 'Intractable' means that they were refractory to nonpharmacological approaches and nonopioid medications, having had adequate trials of nonprescription analgesics, at least two analgesic antidepressants and anticonvulsants, topical agents (lidocaine, capsaicin) and offered surgical stimulation procedures when appropriate. Patients with the CNCP diagnosis of fibromyalgia and most with chronic headache (except one [case 14]) were excluded. Informed consent was obtained from all patients. The photographs have been included with permission from each patient. Reported here in more detail are the diagnostic categories, the opioids and doses used, level of function, disease-specific outcomes, mood, presence of tolerance and duration of follow-up. A standard conversion table was used for calculating morphine equivalents (46).

\section{CASE PRESENTATIONS}

The following cases illustrate a variety of CNCP types, the variability in responsivity to different opioids and doses in the same condition, the combination of different opioids and use with other analgesics to address different pain components, the paucity of intolerable adverse effects, the relief of more than one pain problem in an individual, improvement in disease-specific outcomes and tolerance to adverse effects as doses increase over time.

These $11 \mathrm{CNCP}$ conditions in 17 patients treated with long-term opioid therapy begins with the most common form of CNCP: chronic low back and neuropathic leg pain (three cases), then painful diabetic neuropathy (two cases) and postherpetic neuralgia (one case) (the most studied disorders for RCTs of opioids in CNCP), and then moves to other less common and more intractable forms such as brachial plexus neuropathy, phantom limb pain (two cases), causalgia (two cases), osteomyelitis, arthritis with Crohn's disease, chronic headache, anesthesia dolorosa, post-traumatic orthopedic pain and the central pain of spinal cord vascular malformation (one case each).

Case $1(\mathrm{CM})$ (Figure 2): Chronic non-neuropathic low back pain, high-dose oxycodone

A 50-year-old woman was seen four years previously with a 15-year history of steady, aching, low-back pain increased by movement, especially extension, and rated at 10 on a scale of 1 to 10 (with 10 being the worst pain possible). She was largely bedridden or chair confined. She was able to prepare meals and perform light housework and laundry, slowly, after one $5 \mathrm{mg}$ oxycodone/325 mg acetaminophen, which reduced her pain to $3 / 10$ for approximately $4 \mathrm{~h}$. She used one to two of these per day. Plain x-rays, computed tomography and magnetic resonance imaging revealed nonsurgical, severe, degenerative changes predominantly at the level of the first and second lumbar vertebrae, with severe degenerative facet joint changes. She failed to find relief with 


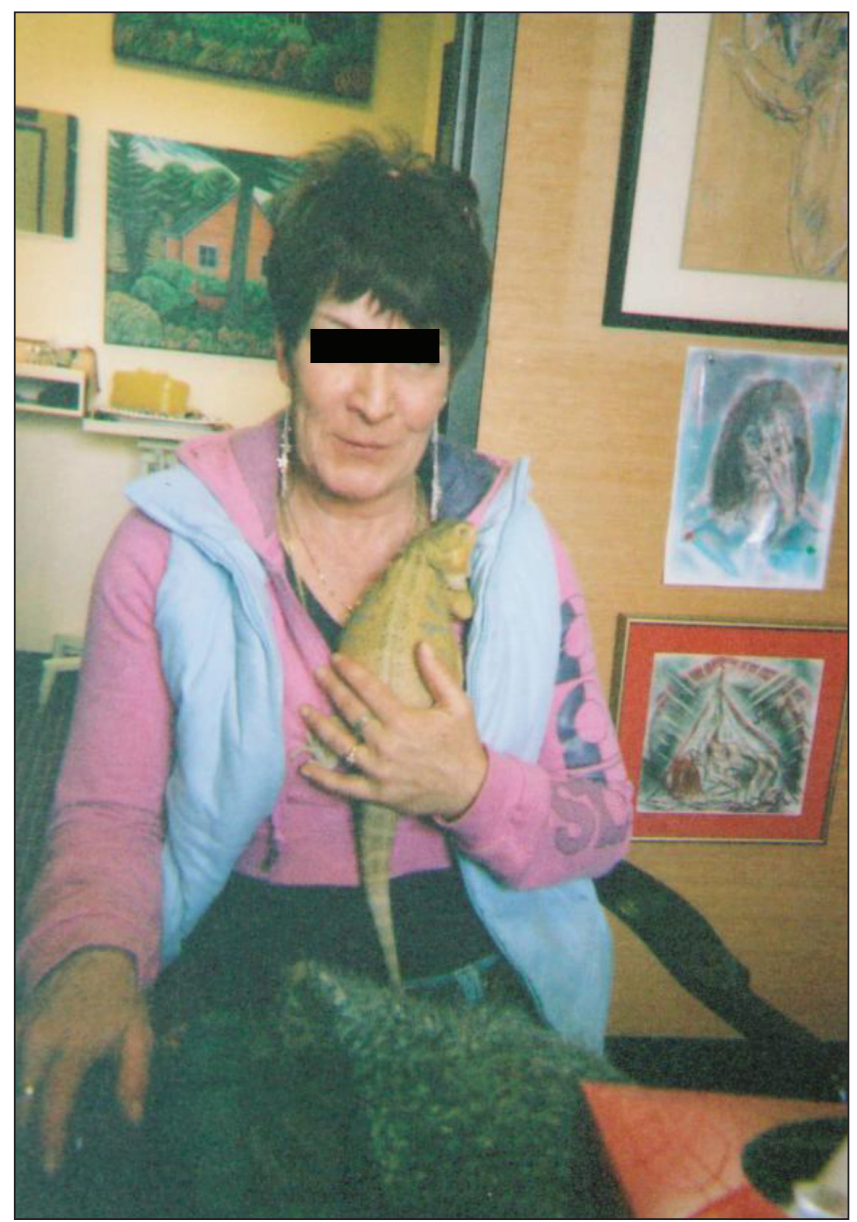

Figure 2) Case 1: CM seen with bearded dragon 'Spike'. She was diganosed with mechanical low back pain and treated with high-dose oxycodone

maximally tolerated doses of gabapentin, tricyclic antidepressants and codeine. She was slowly titrated up to optimal doses of long-acting and as-needed short-acting oxycodone (600 mg morphine equivalents per day). On this regimen, her pain decreased to an average of $2 / 10$ to $5 / 10$, she declared herself up to $75 \%$ improved, was active in activities of daily living, with mild, tolerable constipation, reported a good mood and reported she was satisfied with the result. Her dose has been the same for two years.

Comment: These are good results in a chronic arthritic problem, which is very common (mechanical low back pain), with no evidence of a neuropathic component, refractory to other drugs with no evidence of harm. Further dose escalation and opioid rotation produced no further relief and she declared herself satisfied with the relief and tolerability of the adverse effect of mild constipation. Tolerance has not been an issue because pain and dose have been stable for two years.

Case 2 (VD) (Figure 3): Chronic low back and neuropathic leg pain, high-dose morphine

A 65-year-old man was seen 20 years previously with intractable, steady, low back pain and shock-like and steady radicular pains in the legs in the L5 and S1 root territory bilaterally, all rated at 10/10 at rest both day and night. He was bedridden or chair bound and slept poorly. The physical examination demonstrated bilateral sciatica. He had absent ankle reflexes. His body weight was $49.9 \mathrm{~kg}$. Current imaging of the spine showed scar tissue and he had undergone two previous spinal surgeries for a disc herniation and spinal stenosis, which visualized scar tissue and were without effect. The diagnosis was back pain due to arachnoiditis and scar tissue with bilateral neuropathic leg pain

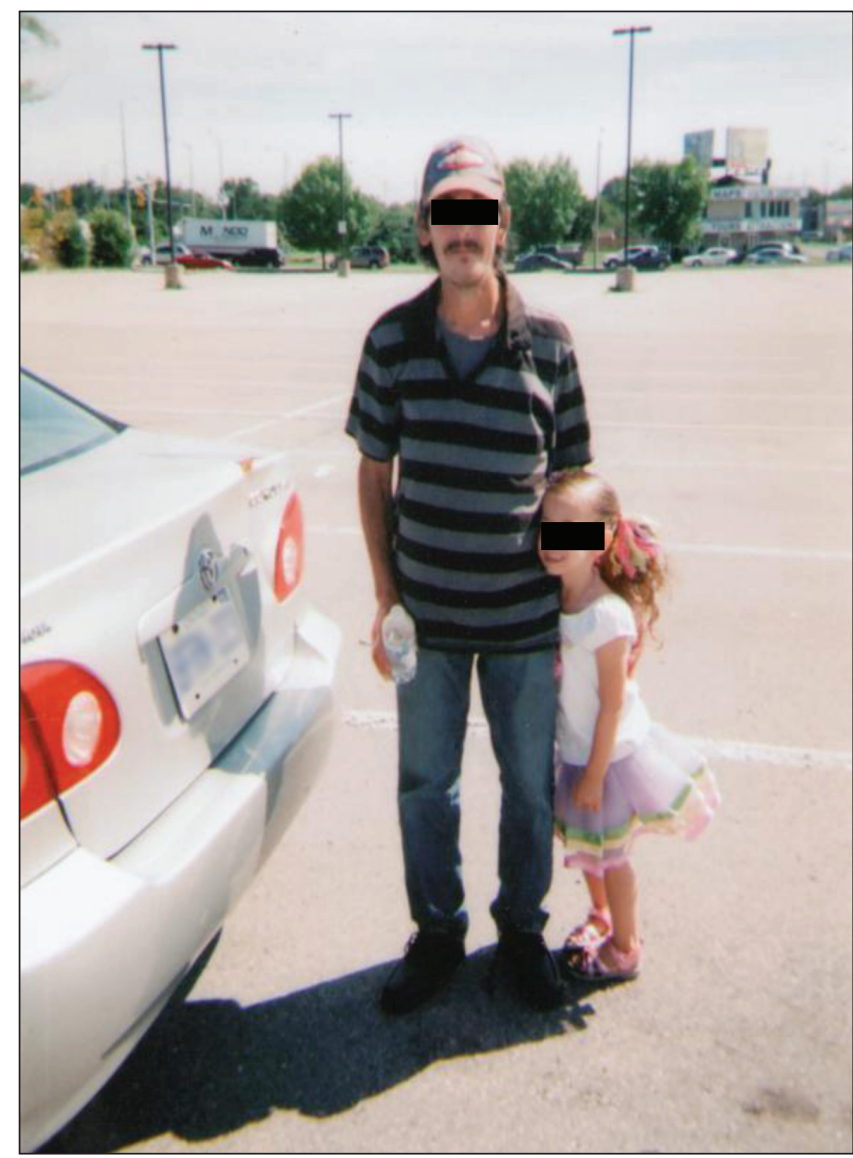

Figure 3) Case 2: On high-dose opioids for back and neuropathic leg pain, VD has been able to enjoy being with his grandchildren for many years. He was previously bedridden

involving the fifth lumbar and first sacral nerve roots. He was placed on long-acting morphine, which was gradually titrated up to $400 \mathrm{mg}$ every $8 \mathrm{~h}$ and, in addition, he used $5 \mathrm{mg}$ oxycodone $/ 325 \mathrm{mg}$ acetaminophen per day as needed (a total of $1300 \mathrm{mg}$ of morphine equivalents per day). This remained the same once a steady state was obtained and his pain was reduced to $2 / 10$ with ordinary activities, down from 10/10 for the previous 14 years. He was able to do more. He did not return to work, but he is active in activities of daily living (not involving significant physical activity). His mood is good and he has no significant side effects, including constipation for which he takes no medication.

Comment: This man, who is of low body weight $(49.9 \mathrm{~kg})$, required a high dose of long-acting morphine combined with short-acting oxycodone as required to relieve his severe low back and neuropathic leg pain. The dose was stable over many years and there was no evidence of tolerance or harm. This made his pain mild at rest and with limited activity. It did not allow significant physical activity or a return to work but, with normal activities of daily living, his pain was well controlled. He experienced no significant side effects and there was no evidence of tolerance. His mood is good, he sleeps well and there has been no evidence of harm over many years.

Case 3 (KM) (Figure 4): Chronic low back and neuropathic leg pain, combination (fentanyl, oxycodone) low-dose opioids and initial sensitivity to several opioids

A 39-year-old postal worker was first seen 13 years previously with a four-year history of steady, aching pain in the low back (8/10) and right leg $(9 / 10)$ in the territory of lumbar nerve roots 4 and 5, and 

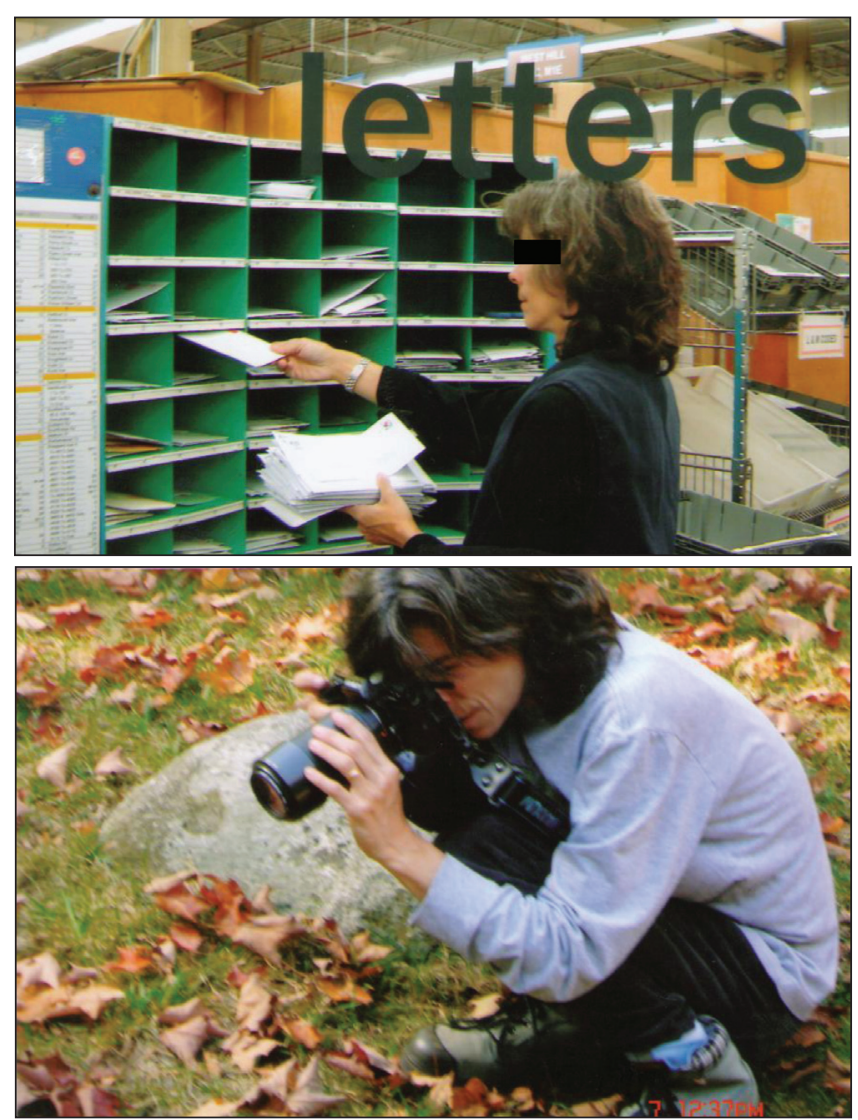

Figure 4) Case 3: Top KM works full-time with back and neuropathic leg pain while on long-term combination opioids (fentanyl/oxycodone). Bottom Back and neuropathic leg pain on opioids at play

sacral 1 . The leg pain was a combination of steady, constant burning pain and shock-like pain in the posterior and lateral legs and feet rated at $8 / 10$. There was an absence of right knee and ankle reflexes. There was no sciatica. This patient experienced electric shock-like pains $(8 / 10)$ several times daily in the same nerve root distribution. She was struggling to work in sedentary, modified duties at the post office and was largely recumbent at home and slept poorly. A magnetic resonance image of the lumbar spine and pelvis showed no disc herniation or stenosis but severe degenerative osteoarthritis. Trials of amitriptyline, nortriptyline, gabapentin, pregabalin and anti-inflammatory drugs were not helpful. Two $5 \mathrm{mg}$ oxycodone/325 mg acetaminophen pills reduced the pain from $8 / 10$ to $5 / 10$. She had trouble tolerating other opioids. She experienced severe nausea and vomiting with transdermal fentanyl. Long-acting oxycodone produced a flu-like syndrome initially, and long-acting morphine was unsatisfactory. Methadone made her vomit. Initially, she was treated with short-acting oxycodone as needed because this was the only drug she could tolerate in low doses. Over time, transdermal fentanyl was reintroduced at $12 \mu \mathrm{g} / \mathrm{h}$ (the lowest dose patch) and gradually increased over months to a $50 \mu \mathrm{g} / \mathrm{h}$ patch every three days with short-acting oxycodone as needed (a total of $200 \mathrm{mg}$ morphine equivalents per day). The same dose has been used now for eight years. On this regimen, her pain is 5/10 when she works, and she is able to work full-time sorting mail and delivering it by truck to rural mailboxes, where she inserts the mail into a bank of individual boxes. She usually takes six weeks off for holidays and goes to her cottage in the summer at which time her pain, on the same dose with reduced activity, is $3 / 10$. She commented that she would be "bedridden and probably suicidal" without the medication. She looks after her elderly mother who is chronically ill and is able to enjoy her hobby of photography.
Comments: In this case, as opposed to the previous, low back and neuropathic leg pain is controlled on a relatively low dose of a combination of opioids for this form of pain (44) and has been for years. The opioid enables this patient to work, care for a dependent family member and enjoy her cottage and hobby. She has had no tolerance over eight years. She has mild constipation, which she manages intermittently with senna. Her mood is stable. She can also do more outside of work. Initially, there was intolerance to opioids at low doses, with mainly gastrointestinal upset. Over the years, with gradual introduction, the nausea and other symptoms, such as fatigue, have abated. She has no major side effects. She failed adequate trials of alternative drug treatments. There is a long follow-up. This is an example of combination low-dose opioid therapy of transdermal fentanyl and oxycodone being optimal for her and the need to tailor treatments to the individual after titration trials of individual opioids and combinations of drugs after the development of tolerance in an opioid-sensitive individual.

Case 4 (AC) (same findings as JF in case 5): Painful diabetic neuropathy, low-dose opioid (oxycodone) for 11 years

This man, now 81 years of age, was seen 11 years previously with a several-year history of severe pain in his feet from painful diabetic neuropathy. He had been diabetic and on glyburide for 10 years. The pain was a steady burning and rated at 10/10 without medication. He was inactive, largely recumbent and had difficulty tolerating bed clothes because of allodynia. He had a distal, symmetrical reduction in touch, pinprick, cold and vibration to the knees, with absent ankle reflexes and allodynia over the feet. He participated in an RCT of long-acting oxycodone, on which he has remained for 11 years. He takes the oxycodone every $12 \mathrm{~h}$ at a dose of $60 \mathrm{mg}$ daily in morphine equivalents, which is unchanged over the past 11 years, with pain levels of $2 / 10$ to $3 / 10$ with normal activity. There has been no evidence of tolerance. His mood is good and he is fully active. If he misses an opioid dose, his pain severity will rise to $10 / 10$. He has no side effects, including constipation, his mood is good and he is active in all activities of daily living and finds that he can tolerate bedclothes on his feet.

Comments: This is an excellent response to low-dose, sustainedrelease oxycodone over 11 years with no evidence of tolerance or any side effects, and full activity with improved disease specific-outcome of tolerating bedclothes because of allodynia relief.

\section{Case 5 (JF) (Figure 5): Painful diabetic neuropathy, high-dose} opioid (oxycodone)

A 62 -year-old woman was seen 4.5 years previously with severe (8/10), steady burning pain and allodynia (especially to bedclothes contact) from painful diabetic neuropathy in the distal legs of six months' duration. She was recumbent for most of the day. She had a distal reduction of touch, pain, cold and vibration sense to the knees, with intact position sense with no weakness and absent knee and ankle reflexes. She failed to find good relief with gabapentinoids or tricyclic antidepressants but responded to short-acting oxycodone. She was titrated upward over several months with long-acting oxycodone twice daily (540 $\mathrm{mg}$ in morphine equivalents per day), a dose that has remained stable for the past two years. Her pain is rated at $2 / 10$ with activity with the opioid, but if she forgets a dose it increases to $8 / 10$ to $9 / 10$. Her mood is good; she is more active in activities of daily living, can tolerate bedclothes now and has no significant adverse effects including constipation.

Comment: This woman has experienced good relief over two years on a stable, high dose of long-acting oxycodone with no obvious harmful effects and improved function. This good relief with a high dose would not have been detected in a previous RCT in which the ceiling dose of oxycodone was $80 \mathrm{mg} /$ day (23). The high dose of opioid required here contrasts with the low dose of the previous patient with the same condition who was older and with a longer duration of pain. There was no evidence of tolerance or hyperalgesia as the dose was increased. She declared that she was satisfied with the relief and tolerability of this drug with stable dosing for two years. 


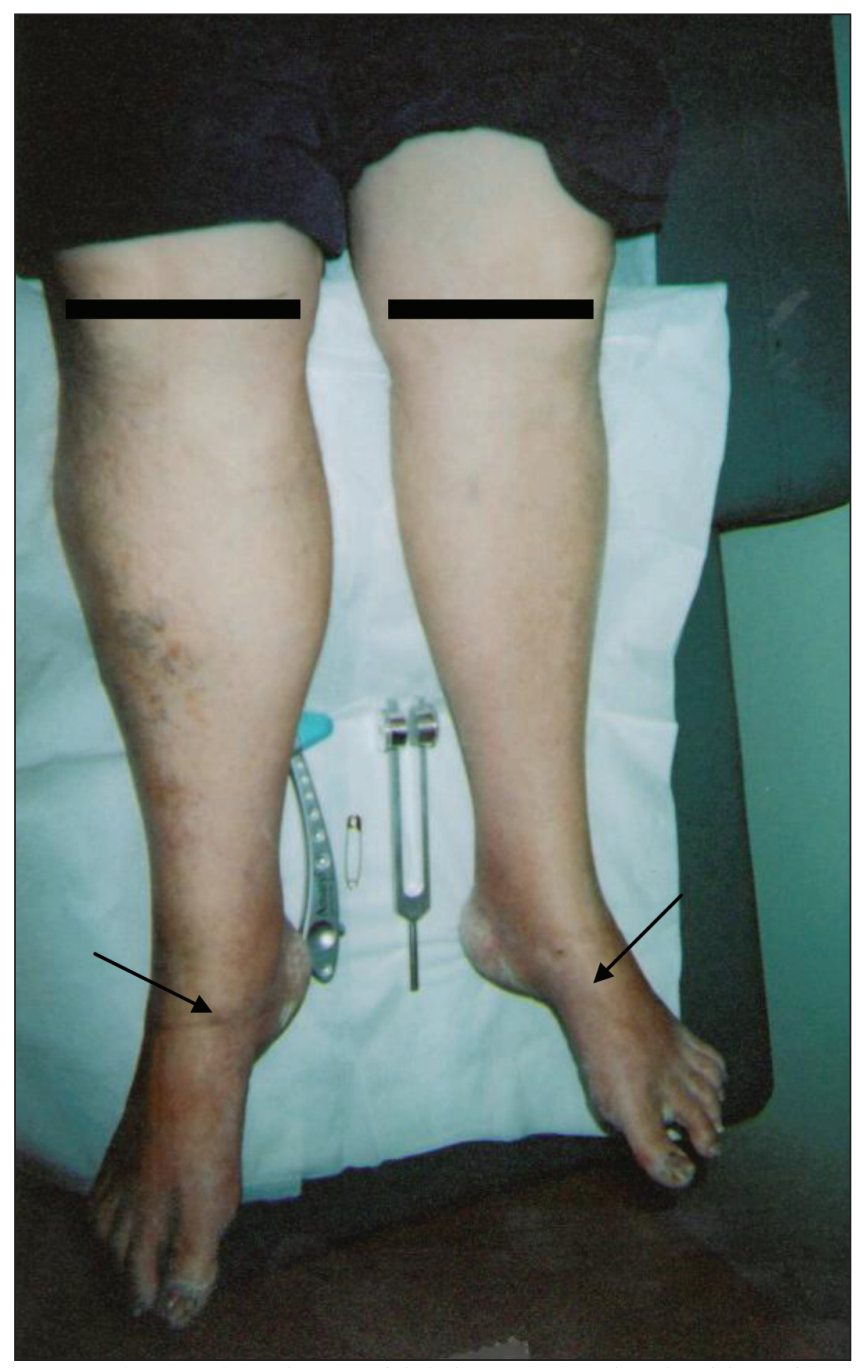

Figure 5) Case 5: JF has painful diabetic neuropathy, distal loss of pinprick, cold, touch and vibration sensation below the solid line in a long stocking distribution, no ankle reflexes and no motor deficit. Allodynia is present over the dorsal and plantar foot (arrows)

Case 6 (RJ) (Figure 6): Postherpetic neuralgia, combination of high-dose oxycodone for pain and low-dose doxepin for postherpetic itch

A 69-year-old man had postherpetic neuralgia for two years in the left forehead in the setting of significant chronic lymphocytic leukemia with white blood cell counts of up to $150 \times 10^{9} / \mathrm{L}$. His pain was severe and he had significant corneal scarring. He experienced steady pain and electric shock-like pains frequently during the day, both averaging 10/10. He also had severe, constant itch. He was not able to work at running his company, in which he was active in performing physically demanding work (home renovation). He was placed on long- and short-acting oxycodone for pain, and doxepin $70 \mathrm{mg} / \mathrm{day}$ for itch. The morphine equivalent dose is $500 \mathrm{mg} /$ day. His pain level has dropped to $2 / 10$ to $3 / 10$ from $10 / 10$, and has been stable for four years without requiring any dose increases. He is able to return to work part-time, although the treatment of his chronic lymphocytic leukemia is increasingly problematic.

Comments: Here is an example of severe NP and pruritis from postherpetic neuralgia that has been well controlled for four years on a combination of high-dose oxycodone for pain and a tricyclic antidepressant (doxepin) for pruritis. His mood has been reasonably good. He can at least work part-time and has no significant side effects except for mild constipation for which he does not take any medication. This is an example of using different drugs for different symptoms

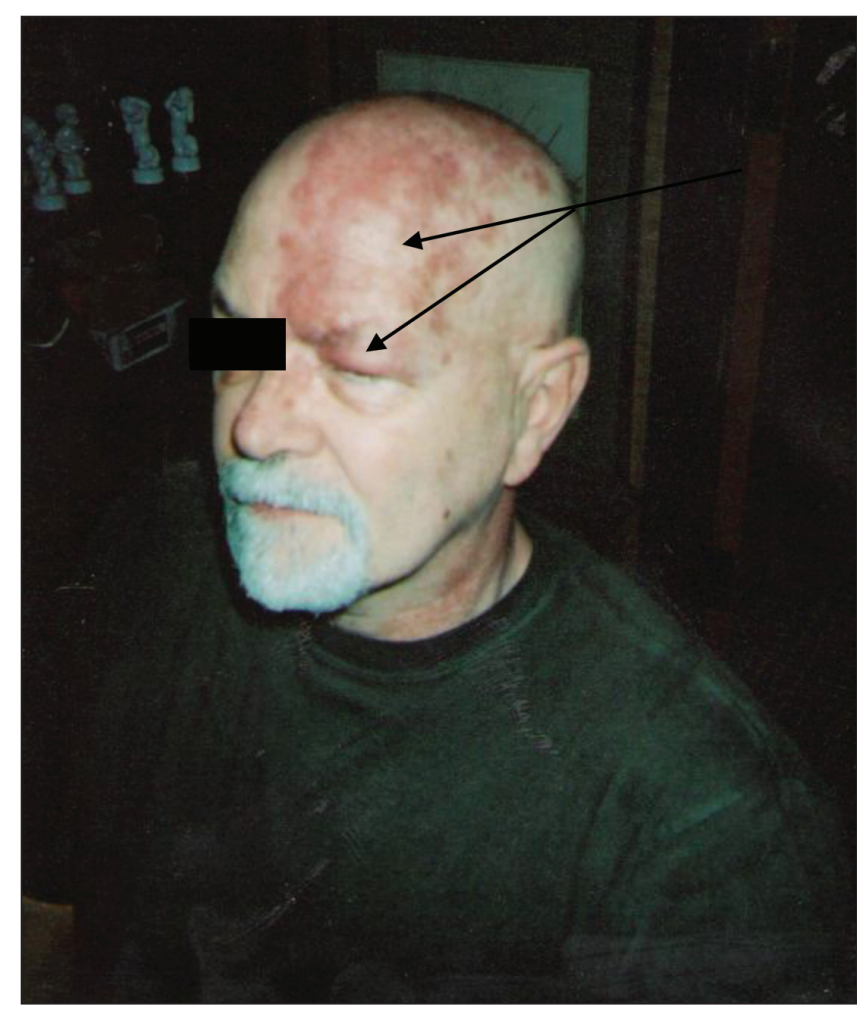

Figure 6) Case 6: RJ found relief of postherpetic neuralgia with opioids. Arrows: loss of sensation and allodynia in ophthalmic division of $V$ nerve, corneal and uveal inflammation and amaurosis

in that doxepin, a tricyclic antidepressant, controls the itch that had been significant after his pain was controlled with the opioid.

Case 7 (MF) (Figure 7): Brachial plexus neuropathy, with progression and long-term pain relief with a combination of a low-dose opioid (oxycodone) with a tricyclic antidepressant (nortriptyline)

A 60 -year-old male teacher was seen 24 years previously with pain in the left hand for 12 years since a left brachial plexus avulsion injury in a motorcycle accident. The original injury was accompanied by concussion with amnesia for two days, and a fracture of his left clavicle. He experienced severe (10/10) burning pain in the medial arm and medial two fingers along with stabbing pains (10/10). He had an atrophic paralyzed left arm with no reflexes and reduced sensation. There was some sensitivity in the medial upper arm but no allodynia. Initially, he did well on nortriptyline $20 \mathrm{mg}$ per day plus four to six acetylsalicylic acid/codeine $30 \mathrm{mg}$ a day. This was later switched to the opioid anileridine, when it was available, at a dose of six to eight $25 \mathrm{mg}$ tablets a day. Approximately 18 years previously, his pain became worse and an increase in his nortriptyline dose to $60 \mathrm{mg} / \mathrm{day}$ was required for constant burning in the medial arm. Approximately eight years ago, his pain increased and he was prescribed long-acting oxycodone with short-acting oxycodone as needed $(90 \mathrm{mg} /$ day in morphine equivalents). This took his pain from $7 / 10$ to $3 / 10$, and he has been on this dose for eight years combined with nortriptyline $10 \mathrm{mg} /$ day. Throughout all of this, he had been able to teach high school fulltime. His mood has been good and he does not have any significant side effects. He does not take anything for constipation. He reported that he was satisfied with the result and continues to be followed regularly.

Comments: This is a very long history (ie, 24 years) of progressive and severe NP from brachial plexus avulsion treated with the combination of low-dose opioid and nortriptyline without evidence of tolerance, a stable dose and full function. He has achieved an excellent response with a very good quality of life and no evidence of harm. 


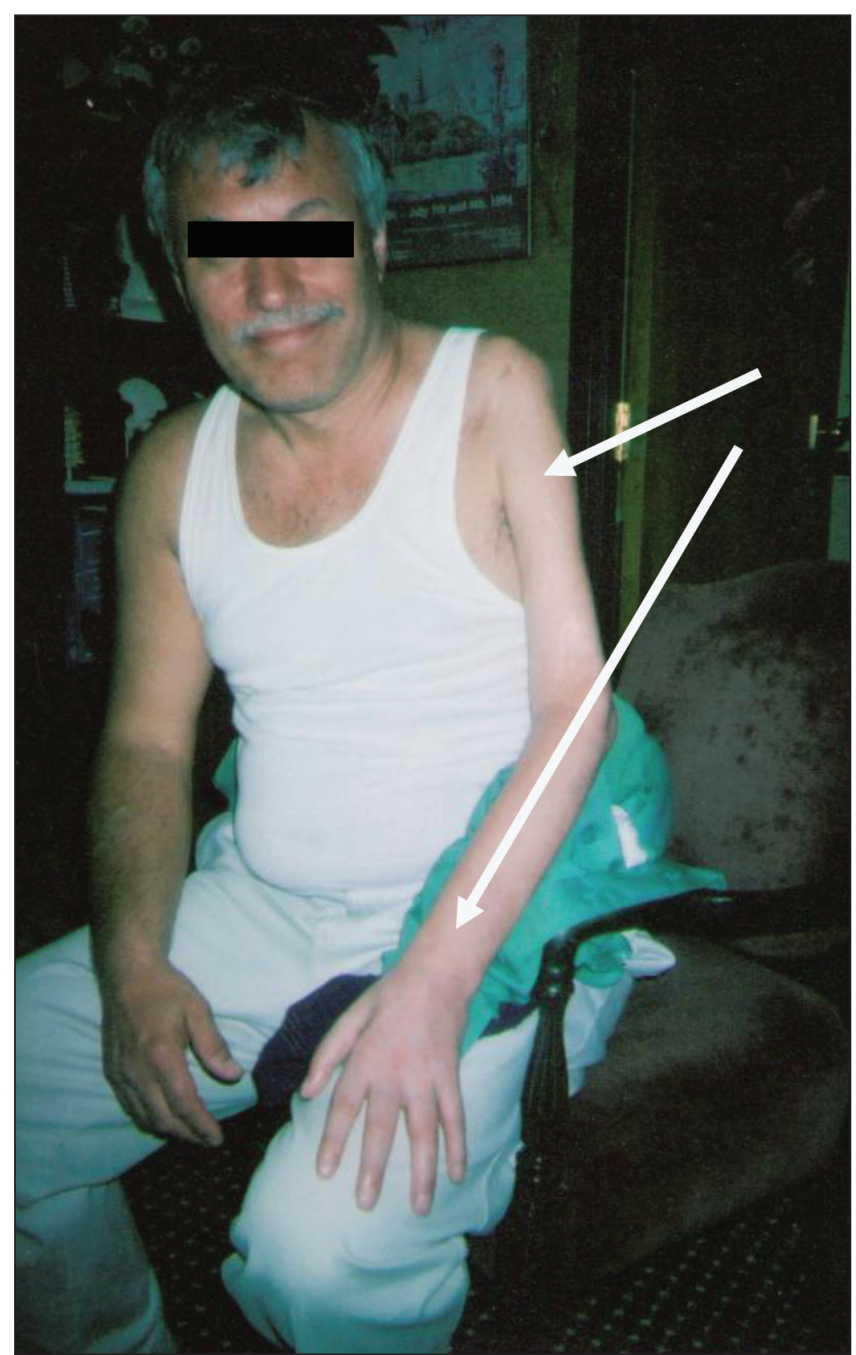

Figure 7) Case 7: MF found relief of progressive neuropathic pain due to brachial plexus avulsion (atrophic, arreflexic, paralyzed arm [arrows]) by a combination of an opioid in a low dose (oxycodone) and a tricyclic antidepressant (nortriptyline) over many years

Case 8 (DW) (Figure 8): Phantom limb pain, long-term low-dose oxycodone

An 81-year-old man had been treated with opioids for bilateral phantom limb pain for eight years before his death from heart disease. He had lost his legs when he stepped on a landmine in World War II in Holland and underwent bilateral above-knee amputations. Thus, he had experienced the phantom limb pain for 53 years. He had severe $(8 / 10)$ phantom limb pain, greater on the left than on the right, and located in the regions of the knee, anterior shin, anterior thigh and Achilles tendon. He experienced a constant, steady, severe pain but also shock-like pains several times a day in the phantom legs. He rated the pain at $8 / 10$ for $24 \mathrm{~h} /$ day unless he took one $5 \mathrm{mg}$ oxycodone $/ 325 \mathrm{mg}$ acetaminophen tablet at night, which enabled him to sleep for a few hours. He described the phantom limbs as feeling like normal limbs in size and position. He had no stump pain. His physical examination was unremarkable, and he had no stump tenderness or sensitivity of the skin. Initially, he experienced good relief with the oxycodone/acetaminophen twice a day, which gave him $12 \mathrm{~h}$ of relief and reduced his pain to $1 / 10$. He was then placed on long-acting oxycodone $(60 \mathrm{mg}$ morphine equivalents per day). He remained the same until his death, with pain levels of $1 / 10$ to $2 / 10$, which climbed to $8 / 10$ if he did not take oxycodone. He returned to Holland in 2000 for the 55th anniversary of its liberation. He was able to drive a car with hand controls. He had no side effects, his mood was good and there was no tolerance.

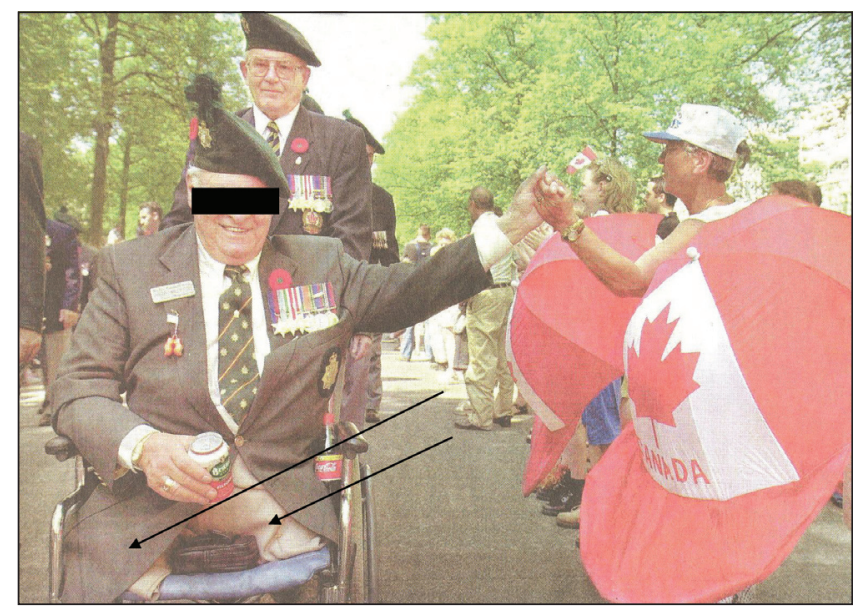

Figure 8) Case 8: DW has a long history of bilateral phantom pain following bilateral above-knee amputations (arrows) with relief by long-term low-dose opioids for many years

Comments: This was an excellent response to a long duration of phantom limb pain (53 years following a World War II injury). He experienced mild pain, at worst, for eight years on oxycodone at a low dose. He was fully active, driving his motorized wheelchair and hand-controlled car. He was not restricted in any way except by the disability from his missing limbs. He showed no evidence of tolerance over several years. He died suddenly of a cardiac arrhythmia. There was no evidence that his medication contributed to his death. His mood was good and he was fully active.

Case 9 (WC) (Figure 9): Intractable phantom limb pain, moderately high dose of opioid (morphine) over many years with moderate relief

A 59-year-old male truck driver was seen with phantom pain in the right arm since an accident one year previously. While changing a truck tire, the tire had exploded and significantly disarticulated his right arm. The blood vessels were torn and, were ligated during surgery. The brachial plexus was resected and the arm was removed with total excision of the humerus but leaving the scapula in place. Postoperatively, he was troubled by drainage and infection. He was left with severe, steady, burning pain in a phantom limb in which the hand felt as if it was in the entire space previously occupied by his arm. He rated his pain as "extremely severe" and 10/10. The physical examination initially showed some drainage from the stump. There was no sensitivity of the skin of the stump to skin stroking but moderate tenderness to firm pressure at the site of the incision; the severe pain was the phantom pain. He then underwent trials of various anticonvulsants including gabapentin, lamotrigine, carbamazepine and tricyclic antidepressants, as well as opioids including morphine, hydromorphone, methadone and transdermal fentanyl. These were titrated to side effects and none of them produced satisfactory pain relief except oxycodone. He titrated up with long-acting oxycodone to a dose of $360 \mathrm{mg}$ morphine equivalents per day. This took his pain from $10 / 10$ to $5 / 10$. He was troubled by constipation, but this was made tolerable with the intermittent use of a commercially available laxative. He has no other major side effects. With the medication, he is able to ambulate and drive his truck. He is able to perform small repairs on his truck with his left arm. He is able to wear a prosthesis. He is able to use his truck to plough snow from his driveway. His mood is irritable and dysphoric. He is intermittently depressed. He has never described being satisfied with the pain relief that he obtains with the oxycodone; however, he says, "Without the drug I would shoot myself."

Comment: This is an example of the attenuation of intractable phantom limb pain without major stump pain by a moderately high dose of one particular opioid, oxycodone, after the failure of other opioids and 


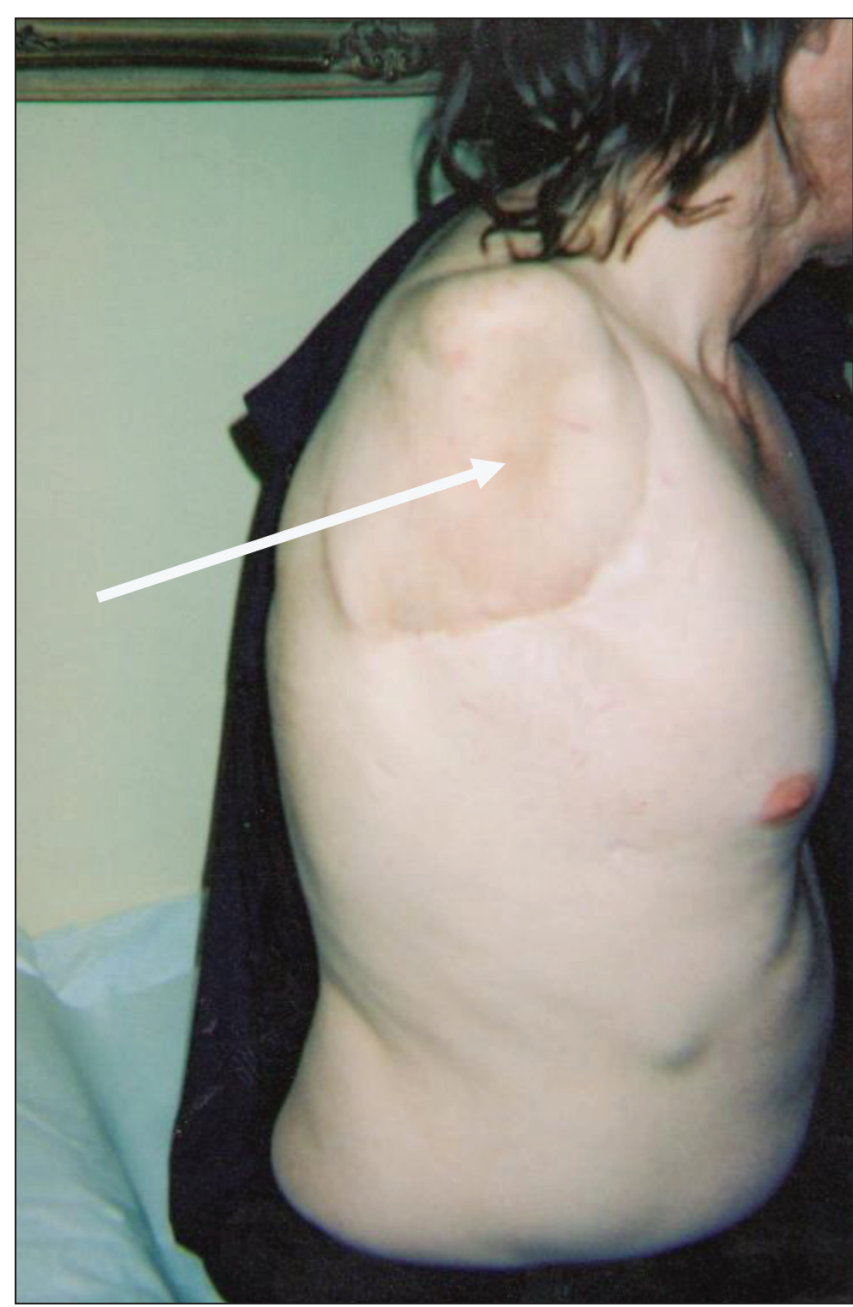

Figure 9) Case 9: WC experiences phantom limb pain, with incomplete but significant relief with high-dose opioids (oxycodone) over many years Arrow: painless stump, scapula preserved

analgesics. Higher doses were tolerated but did not provide any additional relief and he has been on the same dose for eight years. The relief has never been satisfactory for him, but it has been significant in that it reduces his pain by approximately one-half and he is able to be more active.

Case 10 (MR) (Figure 10): Iatrogenic causalgia of the infraorbital nerve relieved for many years with low-dose oxycodone

A 47-year-old woman was seen 21 years previously with pain in the left malar region or infraorbital nerve territory for two years. This had begun following a Caldwell-Luc procedure for sinus problems, immediately after the second operation of that nature. She described steady pain at that time, which ranged from $6 / 10$ to $10 / 10$. The initial physical examination demonstrated reduction in pinprick, cold and touch sensation without allodynia in the left infraorbital nerve territory. Ensuing treatment involved titration of tricyclic antidepressants, gabapentin and carbamazepine, none of which helped. She experienced some relief from $5 \mathrm{mg}$ oxycodone/325 mg acetaminophen and used five to six per day. However, her pain gradually increased over the next few months and years. She was placed on long-acting oxycodone with additional short-acting oxycodone as needed (morphine equivalent $130 \mathrm{mg}$ per day). Over the next year or two, her dose was reduced to $60 \mathrm{mg} /$ day (approximately 10 years ago) and she remained on the same dose. Her pain averages $5 / 10$ with her medications and, with periods of gradual drug withdrawal, will rise to $10 / 10$. With her medications, she is fully active. She has two children. She does not work outside the home. Her mood is good and she does not have any

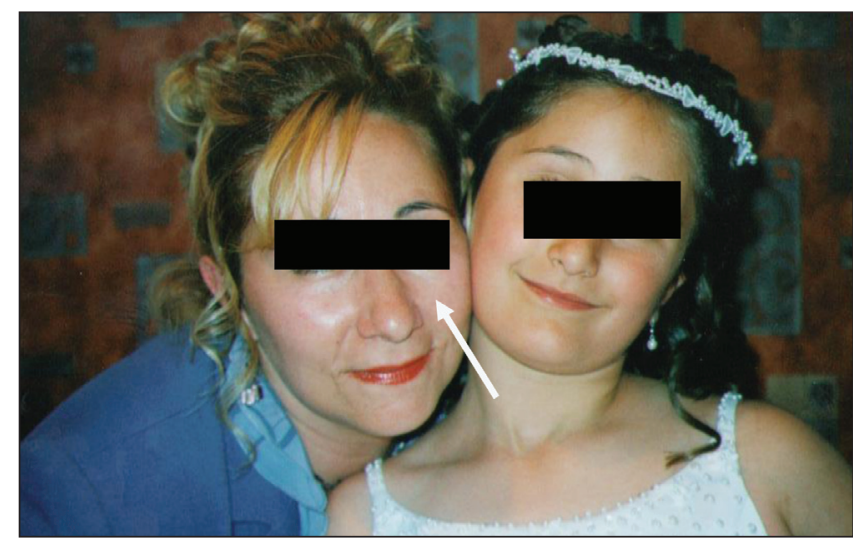

Figure 10) Case 10: MR (left) has iatrogenic infraorbital nerve causalgia Arrow: infraorbital nerve sensory loss

constipation. She declares herself satisfied with the moderate relief she has compared with what it was like without. The provisional diagnosis here is iatrogenic causalgia and the impairment of sensation is not total; therefore, the nerve had been injured but not sectioned. She had some reduction in pinprick, cold and touch sensation over the infraorbital nerve territory.

Comments: This is a very long history with no sign of significant tolerance over many years. In fact, she is using a lower dose than she did 10 years ago. Her mood is good, she is fully active and she has no side effects. She declares herself satisfied with the results. She has been tried on a variety of nonopioids and opioids, including hydromorphone and morphine, with oxycodone giving her the best relief. Increasing the dose does not give her more relief, but produces side effects, so that although her pain can be reduced from severe to moderate, there is a point above which the opioid will not result in more pain relief. This is a similar type of situation to the following, more severe, case of causalgia.

Case 11 (SD) (Figure 11): Severe causalgia of the trigeminal nerve from a bullet wound, on a high-dose opioid with incomplete relief A 60 -year-old man was seen 17 years previously with a seven-year history of right facial pain after a severe fifth nerve injury incurred from a bullet wound suffered during the Vietnam War. He was a soldier in the South Vietnamese army and was shot through the face with a bullet fired from an AK-47 rifle that traversed from the medial left side of his nose and exited around the right ear. This produced sensory loss in the right face, right lower facial paralysis and deafness in the right ear. In addition, he was unconscious and lost a large amount of blood. The pain was mainly in the right malar or infraorbital nerve region. It was rated at 8/10, and was described as burning and hot. A few times a week, he would experience electric shock-line pain in the same area $(8 / 10)$, but it was not triggered by sensory stimuli. He noticed that cold weather worsened the pain. Computed tomography imaging showed bullet fragments around the right zygomatic arch and a fracture of the right zygoma and ethmoid sinuses. Bullet fragments were also seen in the right parotid region. His examination revealed reduced punctate pinprick, cold and touch sensation in all territories of the trigeminal nerve. There was allodynia to skin stroking, skin traction and cold (most marked with skin stroking). He had a right lower facial paralysis with signs of aberrant reinnervation and deafness in the right ear. He has been on long-acting morphine for 17 years, which has varied from $600 \mathrm{mg} /$ day to $1200 \mathrm{mg} /$ day, averaging $880 \mathrm{mg} /$ day. He also uses shortacting oxycodone on an as-needed basis $(60 \mathrm{mg} /$ day morphine equivalents). The pain fluctuation is seasonal in that he is worse in the winter when it is very cold, which is consistent with the cold allodynia.

Comment: This man had a severe fifth nerve injury accompanied by right lower facial paralysis and deafness and unrelieved gunshot wound causalgia, a term coined by Silas Weir Mitchell initially during the American Civil War. He uses the typical nonprompted descriptors of 


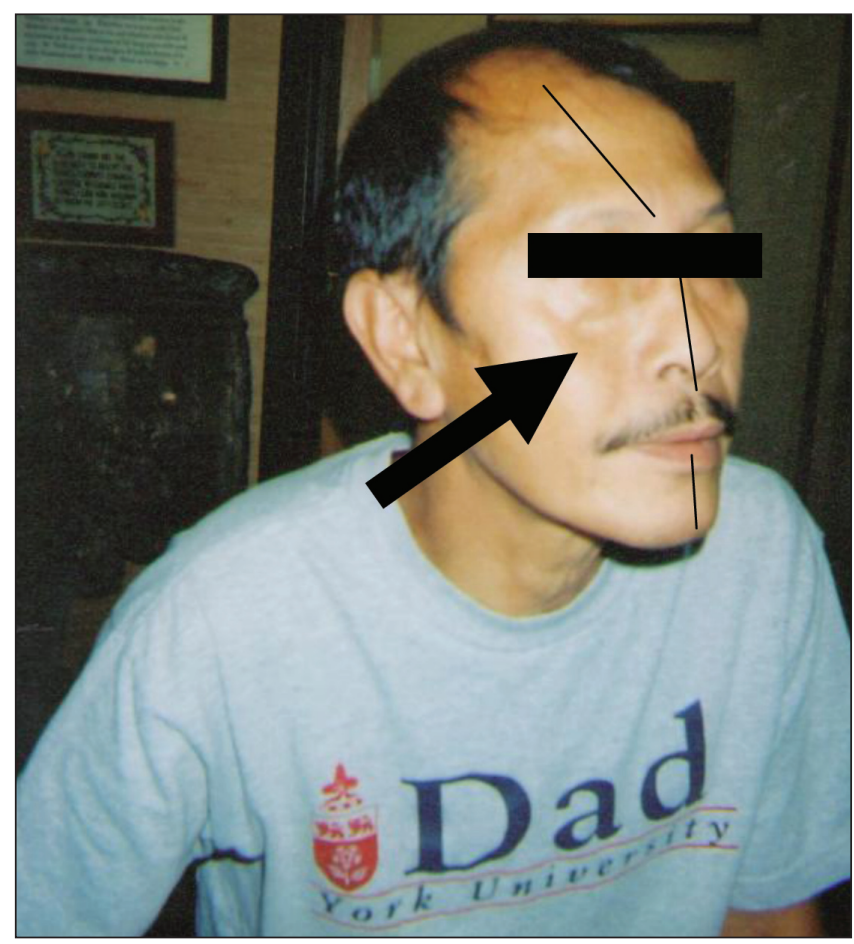

Figure 11) Case 11: SD with causalgia due to bullet wound, moderate relief with high-dose opioids (morphine) over many years. Lines: sensory loss right face; Arrow: main pain in malar region

hot and burning with shock-like pain, along with the findings of sensory loss. He has been on the same dose for 17 years and his pain is reduced from 10/10 to 5/10. Increasing the dose of opioid results in side effects (constipation) and does not produce any further reduction in his pain. He is moderately satisfied with the result he has had. He is able to work and is fully active. His mood is good. He has no constipation. The injury is more severe than that of case 10, but the degree of relief is similar and with a different opioid. He requires much higher doses of opioid, but, similarly, his pain does not fall below 5/10 with increased doses of morphine.

Case 12 (DQ) (Figure 12): Osteomyelitis with good relief with a moderate dose of oxycodone for eight years

A 55-year-old man was initially seen eight years previously with osteomyelitis in his right tibia for five years. There was chronic drainage from a sinus in the right lower leg. This was corroborated by bone scan and he had undergone surgical attempts to eradicate it without success and had been on multiple antibiotics. His pain was in the right lower leg. He was placed on short-acting oxycodone (because he was fearful of the longacting form), which reduced his pain from $8 / 10$ to $4 / 10$. There was a gradual increase from $60 \mathrm{mg} /$ day to $210 \mathrm{mg} /$ day in morphine equivalents. His mood is good and he does not have any severe side effects. He has mild constipation, which he controls with a commercially available laxative and a high fibre diet with fruit. His pain levels remain approximately $2 / 10$ to $3 / 10$. His comment was that the medications had "saved my life." Comment: This is an example of a chronic inflammatory pain that has been well-controlled by a moderate dose of oxycodone for many years with no evidence of tolerance. He has had a stable mood and increased level of activity, although he is not able to return to work. The adverse effect of constipation has been made tolerable by the laxative. The gradual increase in opioid consumption over the years could represent tolerance; however, it could also represent ongoing activity of his disease, which is still active.

Case 13 (RS): Arthritis associated with Crohn's disease with good relief with low-dose oxycodone for 10 years with the additional benefit of relief of diarrhea

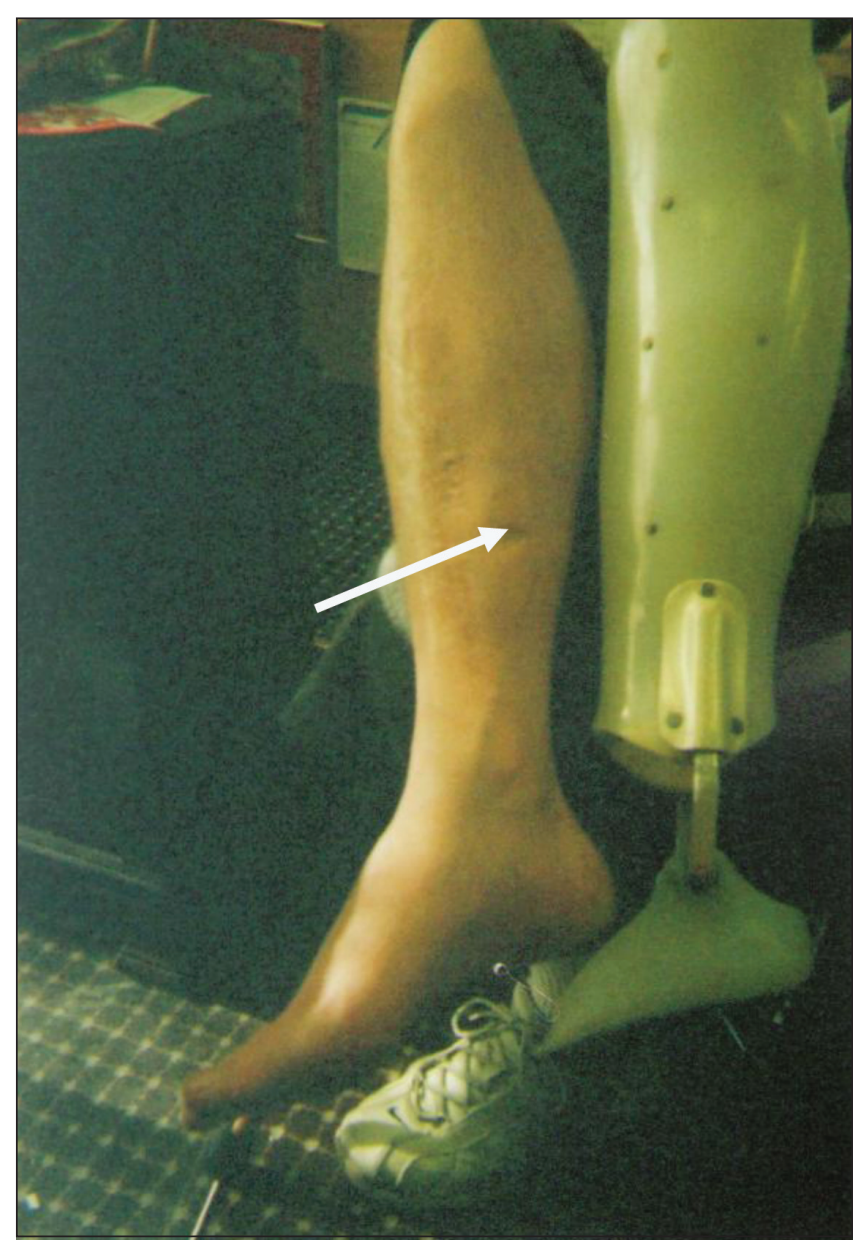

Figure 12) Case 12: DQ found relief from chronic inflammatory pain due to osteomyelitis with moderate-dose opioids (short-acting oxycodone) and a supportive brace over years. Arrow: draining sinus

A 71-year-old man was seen 10 years previously with a long history of Crohn's disease dating back to childhood. He underwent surgeries for this and was on a tumour necrosis factor inhibitor. He developed a Crohn's disease-related arthropathy with severe radiological changes and suffered from severe pain in his neck, shoulders and low back, as well as most of his other joints both proximal and distal, especially the hands. This pain had been refractory to all medication and he was limited as to what he could take in that anti-inflammatory drugs were contraindicated. Currently, he is on long-acting oxycodone plus shortacting oxycodone (morphine equivalents $150 \mathrm{mg} /$ day) He had been on a stable dose for five years. He had the beneficial effect from the opioid of good relief of the Crohn's disease-related diarrhea. His mood is good and he has been been able to continue to work past retirement. He is also physically active, skis and rides horses.

Comments: This is an example of a chronic arthritic condition that has been benefited by long-term opioids without apparent harm. He has experienced a stable mood and improved functioning in that he has been able to work as an internist past retirement, which he said would have been impossible without the opioid. The opioid, additionally, has the beneficial effect of causing a favourable side effect with regard to his Crohn's disease-related diarrhea.

Case 14 (SJ): Chronic daily headaches and arthritis, relief with high-dose opioids with improved function

A 65 -year-old woman was initially seen 15 years previously with a long history of intractable headaches for which she was bedridden. She had seen several neurologists, including international headache experts. She used opioids intermittently, but fairly frequently, in the form of 
short-acting opioids that gave her temporary relief but she would then rebound and expererience a headache again so that most days of the week she expererienced a severe and incapacitating migraine-type headache that was throbbing and accompanied by nausea and vomiting. In addition, she suffered from light and noise intolerance during these episodes. The headache was unilateral but alternating and aggravated by head movement. There was a family history of migraine. Her history of migraine headache had extended back many years and the headaches had become progressively worse. She had undergone extensive investigation. The headaches were refractory to all symptomatic and prophylactic headache medications, which were considerable. She experienced periods of withdrawal from opioids and other drugs for several months, on the assumption that these were medication-induced headaches, and this had not resulted in any improvement and she remained essentially bedridden, only getting up for meals. In the face of this completely intractable chronic tension-vascular, medication-induced headache, a daily regimen of long-acting morphine was instituted with periodic use of short-acting morphine for severe headaches. With this regimen, over many years, her headache problem was significantly improved. She continued to experience two to three headaches per week but they were readily relieved by short-acting morphine. This situation continued for eight years and then she developed a chronic arthritic problem affecting virtually all of her joints accompanied by marked radiological changes of osteoarthritis. The predominant pain problem was pain in her back, hips and legs. This necessitated some increase in the morphine dosage over the years to $600 \mathrm{mg} / \mathrm{day}$. She has remained improved and she lives with and cares for her elderly mother who has Alzheimer's disease. She is able to ambulate. She owns a large mastiff dog that she is able to walk and gains great joy from. She is able to shop and perform activities of daily living. Her quality of life has been significantly improved for many years.

Comments: This is an exceptional instance of chronic opioids being useful initially for a chronic, severely disabling headache (and later osteoarthritis pain) refractory to all preventive and symptomatic medications, drug withdrawal and lifestyle adjustments and who had been seen by several neurologists including internationally recognized headache experts. This is certainly not to be recommended for most headache patients but illustrates that, occasionally, it appears to be a useful approach.

Case 15 (ST): Anesthesia dolorosa, trigeminal neuralgia, multiple sclerosis, low-dose opioid as combination therapy with nortriptyline and carbamazepine

A 62 -year-old man was seen 13 years previously with severe steady burning left facial pain for two years since a glycerol injection for trigeminal neuralgia. The pain was in the left face in all divisions of the trigeminal nerve but maximal in the second division. He had a threeyear history of progressive multiple sclerosis with leg weakness and ataxia. Complicating this was bilateral trigeminal neuralgia for which he had received five glycerol injections. He experienced residual typical trigeminal neuralgia pain in the right lower face triggered by light punctate nasolabial touch, which was shock-like and severe. He had loss of sensation to pinprick, cold and touch over the left face and a spastic paraparesis and arm ataxia. The diagnosis was left trigeminal anesthesia dolorosa due to a glycerol injection and right trigeminal neuralgia associated with multiple sclerosis. Carbamazepine $800 \mathrm{mg} / \mathrm{day}$ completely controlled the right-sided trigeminal neuralgia pain but had no effect on the left-sided steady pain, and neither did gabapentin nor amitriptyline. Nortriptyline $75 \mathrm{mg}$ at bedtime reduced the leftsided steady pain to less severe and the addition of long- and shortacting oxycodone (150 mg morphine equivalents per day) made it mild to moderate (3/10 to 5/10) and tolerable. At follow-up, he had no pain on this regimen but dose reduction resulted in a resurgence of both pains. He has been on the same dose for several years.

Comments: This is an example of NP with two components: the shock-like or jabbing pain of right-sided trigeminal neuralgia and the steady burning pain of left-sided anesthesia dolorosa. Each component

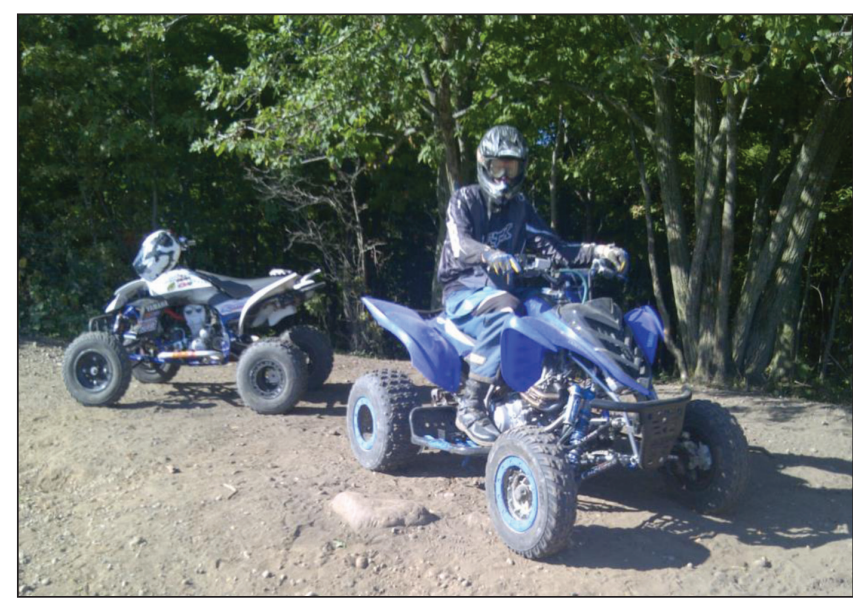

Figure 13) Case 16, JT: Recreational activity possible with relief of chronic post-traumatic orthopedic pain with low-dose opioid (oxycodone)

was relieved by different drug categories: trigeminal neuralgia (as typically) with the anticonvulsant carbamazepine and anesthesia dolorosa with a tricyclic antidepressant and an opioid. This is an example of a low dose of an opioid used in combination therapy with a tricyclic antidepressant for the steady burning pain. The specifically effective drug carbamazepine was necessary for the opioid-resistant pain of the triggered shocks of typical trigeminal neuralgia.

Case 16 (JT) (Figure 13): Post-traumatic orthopedic pain, marked relief and improved function with low-dose oxycodone

A 40-year-old male construction worker was seen eight years previously with intractable severe right groin and iliac crest pain after a work injury in which a concrete wall fell on him 2.5 years previously, resulting in a severe injury to the right lower abdominal musculature and a fractured pelvis involving the right iliac crest. The pain was a steady ache and rated at $3 / 10$ to $4 / 10$ at rest but $9 / 10$ with standing and any activity; thus, he was largely bedridden or chair bound. He mostly watched television. He stated that "To tell you the truth, I could barely sit in a chair and watch television without being in pain before I started taking the medication". He had good relief (0/10 to $2 / 10$ with activity) with long-acting oxycodone $(60 \mathrm{mg}$ morphine equivalents per day) This has persisted for eight years at the same dose with no adverse effects including constipation. He has returned to work buying, refurbishing and selling antique cars full time. He is now able to tolerate the bumpy ride of an all-terrain vehicle.

Comment: Here is an excellent response with low-dose opioid for post-traumatic musculoskeletal pain over many years. He had no adverse effects with full resumption of activities after being largely recumbent or chair bound for two years after the injury, and with no evidence of tolerance.

Case 17 (MD): Central pain due to spinal cord vascular malformation with relief of a disease-specific outcome by combination therapy with low-dose oxycodone and gabapentin A 64-year-old woman was seen 3.5 years previously with a five-year history of severe mid-back and bilateral sixth thoracic nerve root pain. She had undergone surgery 2.5 years before this first visit for successful resection of a spinal cord cavernous malformation at the sixth and seventh thoracic spinal cord segments. She was left with moderate to severe pain. She described a constant, steady pain rated at 5/10 that was described as hot and burning, as well as electric shock-like pain three or four times/day for $2 \mathrm{~h}$ rated at $8 / 10$ to $10 / 10$ more severely on the right than the left. All of this was in the sixth thoracic root distribution. She had marked skin sensitivity (10/10); therefore, she was not able to wear a brassiere or use a seatbelt in the car. She had previously been treated with $3000 \mathrm{mg}$ of gabapentin, which caused lethargy and weight gain. She was also on $50 \mathrm{mg}$ amitriptyline, which caused severe dry mouth, 
drowsiness and constipation. Neither of these had been effective and were subsequently discontinued. She was struggling with her activities of daily living and self-care, and could go for short walks. The physical examination demonstrated a reduction in sensation of pinprick, cold and touch over a wide area from the scapular tip to the iliac crest bilaterally. She had dynamic mechanical allodynia to skin stroking over the fifth and sixth thoracic dermatomes, especially over the breasts. She had noticed that one $5 \mathrm{mg}$ oxycodone $/ 325 \mathrm{mg}$ acetaminophen pill reduced her pain significantly, but her physician was not willing to prescribe this for her. A trial of $5 \mathrm{mg}$ oxycodone/325 mg acetaminophen was instituted, which resulted in an approximately $50 \%$ reduction in pain, so she titrated upward with long-acting oxycodone to $120 \mathrm{mg} /$ day morphine equivalents. This has reduced her pain from $8 / 10$ to $4 / 10$, and relieved the steady burning, shock-like jabs and allodynia. She is maintained on gabapentin $1200 \mathrm{mg} /$ day that she believes augments the oxycodone. She has some tolerable constipation that she manages with bran. Her mood is good. She is able to be more active in that she is able to walk longer and is able to travel by air. She can tolerate a brassiere and wear a seatbelt - disease-specific outcomes from allodynia relief.

Comment: Here is an example of relief of usually difficult-to-treat central pain due to spinal cord disease with a low dose of opioid in combination therapy with gabapentin with previous failure of monotherapy of gabapentinoids and amitriptyline. A disease-specific outcome (the tolerance of clothing) was relieved. The side effects, including constipation, were tolerable and easily managed. She has been on the same dose now for two years.

\section{DISCUSSION}

The cases discussed in the present article were selected and updated to 2011 from a published survey (44) based on experience with 84 patients with intractable, severe, disabling CNCP treated with opioids over a median of 8.5 years (up to 2007). They add to a previously published and updated (to 2011) case series of 10, also from this larger group (45).

From the survey of the 84 subjects, it was concluded that opioids were moderately effective and safe in the long term. Most subjects reported at least $50 \%$ or greater pain relief and a moderate improvement in disability. Functional status (47-49), mood (50) and HRQL (51) were not severely affected. Problematic use, tolerance and serious adverse effects, including constipation, were not major problems. The surprising lack of significant side effects may be attributed to tolerance and/or selection (the previous dropping out of subjects intolerant to opioids). Constipation relief was individualized, but usually did not require aggressive treatment. In the back and neuropathic leg pain group, which constituted the largest group of patients $(n=24)$, the median dose was $510 \mathrm{mg} /$ day in morphine equivalents (versus $220 \mathrm{mg} /$ day for the entire group). The most common opioid used was oxycodone, followed by morphine, transdermal fentanyl and hydromorphone.

Case reports and case series are regarded as occupying a lower tier of medical evidence. RCTs and the guidelines based on these studies are viewed as the gold standard but have their limitations in CNCP such as NP. Several RCTs suggest that opioids provide short-term relief of NP (which constitutes a substantial portion of CNCP) (18-27). These data indicate that opioids relieve steady burning, shock-like pain and skin sensitivity in postherpetic neuralgia and painful diabetic neuropathy, as well as improve the quality of life $(18,23)$. RCTs of heterogeneous CNCP, even of NP, may not capture the subset of subjects who do well. Moreover, RCTs also do not extend past eight to 12 weeks in duration, and long-term studies (months and years) are difficult to perform, especially those involving opioid and nonopioid combinations. Thus, there are major deficiencies in the literature with regard to generalizability and long-term data. Furthermore, outcome measures used in RCTs may not capture disease-specific outcomes such as the relief of skin sensitivity (allodynia) preventing wearing clothing (in postherpetic neuralgia, postaortocoronary bypass NP and the NP of the post-mastectomy pain syndrome), the tolerance of bed clothes in painful diabetic neuropathy, the wearing of a prosthesis in phantom and stump pain, and the ability to eat, speak and brush teeth in trigeminal neuralgia. Additionally, in our experience, it is becoming more difficult to recruit suitable patients, even with common conditions, for RCTs perhaps because of the moderate success of such drugs as gabapentinoids and antidepressants in primary care. Guidelines based on systematic reviews and RCTs may also suffer from a dearth of a good evidence base or good external validity and, thus, may be less useful (absence of proof is not proof of absence) to the practitioner than expert opinion. Eighty per cent of drug trials in NP have been performed in postherpetic neuralgia and painful diabetic neuropathy (15); thus, they have limited applicability (external validity) to other NP conditions, many of which are more intractable and uncommon and, therefore, difficult to study by RCT. Less common and more intractable NP conditions include spinal cord injury pain, phantom limb pain, incisional neuralgias (postmastectomy, post-thoracotomy), central poststroke pain or those with different pain mechanisms. Negative trials of opioids and nortriptyline in intractable conditions such as sciatica (27) and amitriptyline in HIV neuropathy are examples (52). As well, these guidelines may not be applicable to uncommon NP conditions that, because of their scarcity, are not amenable to RCTs (eg, anesthesia dolorosa, causalgia, brachial plexus avulsion and syringomyelia).

Current long-term data regarding opioids in CNCP are both epidemiological $(5-7,36-38)$ and observational (39-44). The favourable impact of these drugs in specific pain problems in individuals and in the long term also may not be captured by epidemiological and observational data, and spurious causality may be attributed to negative associations of opioids and quality of life.

Epidemiological studies have suggested problems with long-term use of opioids, including a low HRQL (36-38). One conclusion was that opioid use did not fulfill outcomes of relief, HRQL and functional capacity. Toblin et al (8) reported similar results in Kansas (USA) regarding the association of opioid use with poor health outcomes. However, Sjogren (5) and Sjogren et al (7) concluded that "the Danish surveys and the Toblin et al study (8) demonstrate the limitations of cross-sectional data that attempt to assess the consequences of the extensive and liberal use of opioids in CNCP".

There are several observational long-term studies in the literature (39-44). Some previous observational studies have reported that opioids may be effective in the long term $(42-44)$, but caution about the lack of functional improvement and raise concern about the abuse potential of these drugs $(40,41)$. Observational studies of large numbers of patients do not capture the individual nuances of a case report, which flesh out an individual response. A photograph can have a powerful impact. The clinical experimental approach of trial and error still carries merit. The case report captures a real-world effect and includes patients who may be excluded from an RCT because of age, concomitant disease or drugs, or whose responsivity may be missed because of dosage allowances.

The selected case series in the present article reports the management details of a variety of CNCP conditions that are, as in the larger group from which they are derived, substantially or moderately relieved with improved functioning and quality of life by a variety of different opioids. The latter were sometimes in high doses, either in monotherapy or in combinations of long- and short-acting opioids. These CNCP conditions include uncommon and difficult-to-treat NP problems but also arthritic and visceral pain. The cases capture issues less available elsewhere, such as disease-specific outcomes (ability to wear clothing with NP or use of a prosthesis in phantom limb pain), combination therapy, concurrent addiction history and long-term follow-up. It is important to put a face on these patients in view of the intensity of concern raised by addiction specialists, journalists and the public about the putative abuse and mortality from opioids, even in CNCP patients.

Silas Weir Mitchell, arguably the most famous neurologist in North America in the 19th century, wrote from his American civil war experience that, "For the easing of neurotraumatic pain we tried in 
turn the whole range of medicines and none of them, save morphia, seemed to be the slightest value...the morphia salts are invaluable" (53). Because of the widespread availability of opioids in patent medicines without prescription, and recommendations, such as that of William Hammond, the surgeon general of the army at that time, to add cocaine to wine as a tonic, there arose a major problem leading to opioid phobia generated by the availability and liberal use of opioids. This persisted until the mid-20th century when the hospice movement demonstrated the utility of oral morphine for cancer pain. This experience gradually penetrated the treatment of CNCP in refractory cases. Perhaps we now have an analogous situation in which opioids are in widespread use and readily available to those who would abuse and divert them. Inadequate education of prescribers has very likely produced excessively liberal use with inadequate screening and selection of patients, inappropriate use and limited follow-up. An opioid treatment guideline (3) concluded that the evidence for the use of opioids in $\mathrm{CNCP}$ is limited, that the evidence for screening tools predicting addiction is also limited and that clinical decisions regarding the use of opioids in CNCP need to be made based on weak evidence. They also state that there is some evidence that opioids are effective for some patients with CNCP. On the basis of different perspectives, it may be, as in the folktale of the blind men and the elephant, that we are coming to different conclusions.

The strength of these case reports is the identification of a population of complex patients with intractable pain, some of whom may be excluded or missed by RCTs because of age, concomitant disease, or drugs and dosage allowances, and who benefit from opioids over the long term in high doses, in combination therapy and often in diseasespecific ways. These data capture information that may be inaccessible to RCTs of monotherapy or combination therapy in selected patients, even over the short term, and by other observational and epidemiological data. Despite having good internal validity, RCTs may not address real-world contexts. The limitation is that these data may not be generalizable to a larger population because of the probable selection of patients who benefit and who do not experience intolerable adverse effects. The bias of subject and observer is always a factor in nonblinded studies. It is unlikely that the natural history of pain resolving with time will occur in cases of intractable CNCP of months and years duration. Additionally, any placebo effect from the charisma of the observer or hopes of the subject will likely wear off with longterm follow-up, which is feasible, over years, with a case series.

It is possible that some of our patients are abusing or diverting opioids, but trust is essential, as is careful screening and follow-up, and there has been minimal evidence of this over many years except for 12 instances (one of diversion, 11 of abuse) over 30 years in all patients with an opioid trial for CNCP. The 11 patients had a known addiction history and were given an opioid trial because of a severe concomitant chronic pain condition. Four of the original 84 of these patients with an addiction history exhibiting problematic use were continued on opioids, and all were discharged except one who, after treatment of bipolar disorder, has not encountered a problem for 16 years. These problematic patients were all recorded from a population followed over many years. This group averaged between 80 and 100 patients at any one time with some flux, but there may be others with problematic use who were lost to follow-up.

\section{CONCLUSIONS}

Opioids appeared to be safe and moderately effective for selected patients with CNCP, most of whom had NP. High doses of opioids are sometimes required. Escalating doses of opioids have not been problematic because beyond a certain plateau, with reasonable relief, further dose increases did not result in more pain relief. Refractory constipation and other side effects have also been uncommon. The data in our survey provide evidence of an improvement in quality of life and physical functioning, sometimes disease-specific, of a moderate degree, predominantly in a change from being bedridden to being able to perform activities of daily living. For many patients, it is not realistic to gain complete relief or even a reduction to mild pain. However, often a change from severe to moderate or less-severe pain, even without any change in function, is a great improvement for many sufferers and an acceptable outcome in their view. Managing carefully selected CNCP patients with opioids with expert care is very similar to any other population of patients with chronic disease. They come regularly (every three months) for monitoring and prescriptions, and are usually monotonously the same regarding outcomes and doses of drug once stabilized. They rarely call for any reason in the interim period.

Of course, great care must be taken with this practice. Detailed guidelines are available $(3,46)$. Simplified pragmatic guidelines are feasible:

- prescribers must have adequate education in this area regarding screening, pain assessment and treatment (opioids as a last resort, opioid pharmacology, principles of misuse and addiction);

- screening of potential patients is critical (as with the revised Screener and Opioid Assessment for Patients with Pain (54) and the Opioid Risk Tool (55). Of particular importance are a personal and/or family history of addiction, significant psychiatric illness (bipolar disorder, schizophrenia, obsessive compulsive disorder, attention deficit disorder) and childhood psychological and/or physical and sexual abuse;

- it is prudent to have a verbal or written contract with patients regarding rules to be followed with these drugs (one prescriber and pharmacy, secure drug location, zero tolerance for diversion or abuse);

- documentation is essential (drug and dose, pain severity, relief, adverse effects, functional status, quality of life, mood, physical findings) at each visit;

- regular follow-up with prescription copies and charting is prudent (our Ontario regulatory body's attitude is that if it is not documented you did not do it!);

- ideally, patients who may require vigilance (doses $>200 \mathrm{mg}$ morphine equivalents per day) are possibly best managed by a pain clinic or pain specialist;

- if indicated, opioid withdrawal should be gradual to avoid physical withdrawal symptoms; and

- qualitative urine testing, if negative, may suggest diversion, and if positive for other drugs such as benzodiazepines, cocaine and heroin, an abuse issue.

Further information is required about patient selection regarding who should be treated. Patients should have moderate to severe pain with adequate trials of nonopioids and nonpharmacological approaches when appropriate. Patients with refractory NP, or visceral and arthritic pain are suitable. This experience indicates that patients with fibromyalgia, myofascial pain, medically unexplained pain as well as most chronic headaches are usually not good candidates for opioid treatment. More data are needed as to the utility of screening tools regarding the potential for problematic opioid use. As well, further long-term observational data are needed to capture the impact of this approach for patients with CNCP in whom all other approaches have been exhausted.

\section{SUMMARY}

The case summaries in the present article document the benefit of opioids, often in high doses, for selected patients with very severe and intractable CNCP over many years. Even with these powerful drugs, the results can be less than optimal, although still significant to the sufferer. Of critical importance is preventing the misuse of prescription opioids, but also, vitally, we must not deny access to those with acute pain, cancer pain and CNCP in desperate need of them. Another great issue in the treatment of CNCP is the limited efficacy of all drugs and nonpharmacological approaches in monotherapy or in combination in many of our patients. We desperately need new ideas about mechanisms, and how to best use our existing remedies and novel treatment approaches 
And so these wise men

Disputed loud and long

Each in his own opinion

Exceeding stiff and strong

Though each of them was partly right

And each was partly wrong.

Adapted from the folk tale: The Blind Men and the Elephant

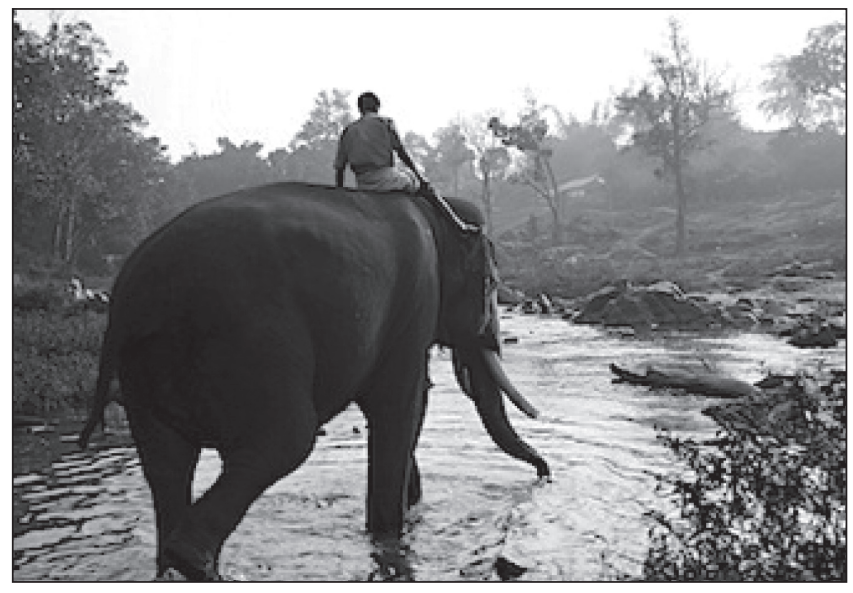

DISCLOSURE: The author has no conflict of interest regarding this article.

ACKNOWLEDGEMENTS: The author acknowledges the invaluable assistance of Mary Chipman and Jack Williams for many suggestions, corrections and comments.

\section{REFERENCES}

1. Ballantyne J. Opioids around the clock? Pain 2011;152:1221-2.

2. Dhalla I. The Medical Post, October 4, 2011, page 75.

3. Chou R, Fanciullo GJ, Fine PG, et al. Clinical guidelines for the use of chronic opioid therapy in chronic non-cancer pain. J Pain 2009;10:113-30.

4. Moulin DE, Clark AJ, Speechley M, Morley-Forster PK. Chronic pain in Canada - prevalence, treatment, impact and the role of opioid analgesia. Pain Res Manage 2002;79:179-84.

5. Sjogren P. Epidemiology of pain and critical issues in opioid use. Pain 2011;152:1219-20.

6. Eriksen J, Jensen MK, Sjogren P, Ekholm O, Rasmussen NK. Epidemiology of chronic non-malignant pain in Denmark. Pain 2003;106:221-8.

7. Sjogren P, Ekholm O, Peuckmann V, Groenbaek M. Epidemiology of chronic pain in Denmark: An update. Eur J Pain 2009;13:287-92.

8. Toblin RL, Mack KA, Perveen G, Paulozzi LJ. A population based survey of chronic pain and its treatment with prescription drugs. Pain 2011;1152:1249-55.

9. Gureje O, Von Korff M, Simon GE, Gater R. Persistent pain and well-being: A World Health Organization study in primary care. JAMA 1998;280:147-51.

10. Joransen DE. Improving availability of opioid pain medications: Testing the principle of balance in Latin America. J Pall Med 2004;7:105-14.

11. Claussen TG, Eriksen J, Borgbjerg FM. Legal opioid consumption in Denmark in 1981-1993. Eur J Clin Pharmacol 1995;48:321-5.

12. Dhalla IA, Mamdani MM, Silviotti ML, Kopp A, Qureshi O, Juurlink DN. Prescribing of opioid analgesics and related mortality before and after the introduction of long-acting oxycodone. CMAJ 2009;181:891-6.

13. Okie S. A flood of opioids, a rising tide of deaths. N Eng J Med 2010;363;1981-5.

14. Gomes T, Juurlink DN, Dhalla IA, Mailis-Gagnon A, Paterson JM, Mamdani MM. Trends in opioid use and dosing among socioeconomically disadvantaged patients. Arch Int Med 2011;171:686-91.
15. Watson CPN. External validity of pharmaceutical trials in neuropathic pain. In: Rothwell PM, ed. Treating Individuals: From Randomized Trials to Personalized Medicine. Philadelphia: Elsevier, 2007:121-30.

16. Watson CPN, Gilron I, Sawynok J. A qualitative, systematic review of head-to-head randomized, controlled trials of oral analgesics in neuropathic pain. J Pain Res Manage 2010;15:147-57.

17. Watson CPN, Gilron I, Sawynok J, Lynch ME. Nontricyclic antidepressants and pain: Are serotonin norepinephrine re-uptake inhibitors (SNRIs) any better? Pain 2011;152:2206-10.

18. Watson CPN, Babul N. Oxycodone relieves neuropathic pain: A randomized trial in postherpetic neuralgia. Neurology 1998;50:1837-41.

19. Harati Y Gooch C, Swensen M, et al. Double blind randomized trial of tramadol for the treatment of the pain of diabetic neuropathy. Neurology 1998;50:1842-6.

20. Sindrup SH, Andersen G, Madsen C, et al. Tramadol relieves pain and allodynia in polyneuropathy: A randomized, double-blind, controlled trial. Pain 1999;83:85-90.

21. Rowbotham MC, Twilling L, Davies PS, Reisner L, Taylor K, Mohr D. Oral opioid therapy for chronic peripheral and central neuropathic pain N Engl J Med 2003;349:1223-32.

22. Raja SJ, Haythornethwaite JA, Papagallo M, et al. Opioids versus antidepressants in postherpetic neuralgia: A placebo-controlled study. Pain 2002;94:215-24.

23. Watson CPN, Moulin D, Watt-Watson J, Gordon A, Eisenhoffer J. Controlled-release oxycodone relieves neuropathic pain: A randomized controlled trial in painful diabetic neuropathy. Pain 2003;105;71-7.

24. Gimbel JS, Richards P, Portenoy RK. Controlled-release oxycodone for pain in diabetic neuropathy: A randomized controlled trial. Neurology 2003;60:927-34.

25. Boureau F, Legallicier P, Kabir-Ahmadi M. Tramadol in postherpetic neuralgia: A randomized, double-blind, placebo-controlled trial. Pain 2003;104:323-31.

26. Gilron I, Bailey JM, Tu D, Holden RR, Weaver DF, Houlden RL. Morphine, gabapentin or their combination for neuropathic pain. N Engl J Med 2005;352:1324-34.

27. Khoromi S, Cui L, Nackers L, Max MB. Morphine versus nortriptyline and their combination in chronic lumbar root pain. Pain 2007;130:66-75.

28. Jaffe J. Opiates: Clinical aspects. In: Lowinson JH, Ruiz P, Millman RG, eds. Substance Abuse. A Comprehensive Textbook. Baltimore: Williams and Wilkins, 1992:186-94.

29. Sees KL, Clark KW. Opioid use in the treatment of chronic pain: Assessment of addiction. J Pain Symptom Manage 1993;8:257-64.

30. Savage SR. Long-term opioid therapy: Assessment of consequences and risks. J Pain Symptom Manage 1996;11:274-86.

31. Sacerdote P, Manfredi B, Manttegazza P, Panerai AE. Antinociceptive and immunosuppressive effects of opiate drugs: A structure-related activity study. Br J Pharmacol 1997;121:834-40.

32. Sjogren P, Olsen AK, Thomsen AB. Impaired neuropsychological performance in chronic non-malignant pain patients receiving longterm oral therapy. J Pain Symptom Manage 2000;19:100-8.

33. Mao J. Opioid-induced abnormal pain sensitivity: Implications in clinical opioid therapy. Pain 2002;100:213-7.

34. Rajogopal A, Vassilopoulou-Sellin R, Palmer JL, Kaur G, Brera E. Symptomatic hypogonadism in male survivors of cancer with chronic exposure to morphine. Cancer 2004;100:851-8.

35. Vallejo R, de Leon-Casasola O, Benyamin R. Opioid therapy and immunosuppression. A review. Am J Ther 2004;11:354-65.

36. Becker N, Thomsen AB, Olsen AK, Sjogren P, Bech P, Eriksen J. Pain epidemiology and health related quality of life in chronic non-malignant pain patients referred to a Danish multidisciplinary pain center. Pain 2000;73:393-400.

37. Jensen MK, Thomsen AB, Hojsted J. 10 year follow-up of chronic non-malignant pain patients: Opioid use, health related quality of life and health care utilization. Eur J Pain 2006;10:423-33.

38. Eriksen J, Sjogren P, Bruera E, Ekholm O, Rasmussen NK. Critical issues in chronic non-cancer pain: An epidemiological study. Pain 2006;125:172-9.

39. Taub A. Opioid analgesics in the treatment of chronic intractable pain of non-neoplastic origin. In: Kitahata LM, Collins D, eds. Narcotic Analgesics in Anesthesiology. Baltimore: Williams and Wilkins. 1982:199-208. 
40. Portenoy RK, Foley RM. Chronic use of opioid analgesics in nonmalignant pain. Report of 38 cases. Pain 1986;25:171-86.

41. Tennant FS, Robinson D, Sagherian A, Seecof R. Chronic opioid treatment of intractable non-malignant pain. NIDA Res Monogr 1988;81:174-80.

42. Zenz M, Strumpf M, Tryba M. Long-term oral opioid therapy in patients with nonmalignant pain. J Pain Symptom Manage 1992;7:69-77.

43. Watson CPN, Watt-Watson J, Chipman ML. Chronic non-cancer pain and the long term utility of opioids. Pain Res Manage 2004;9:19-24.

44. Watson CPN, Watt-Watson JH, Chipman MA. The long-term efficacy and safety of opioids: A survey of 84 selected patients with intractable chronic non-cancer pain. Pain Res Manage 2010;15:213-8.

45. Watson CPN. Opioids in chronic non-cancer pain: Some blind men and an elephant? Scand J Pain 2012;3:5-13.

46. Furlan AD, Reardon R, Weppler C. Opioids for chronic non-cancer pain: A new Canadian practice guideline. CMAJ 2010;182:923-30.

47. Daut IE, Cleeland CS, Flanery RC. Development of the Wisconsin Brief Pain Questionnaire to assess pain in cancer and other diseases. Pain 1983;17:197-210.
48. Tait RC, Chibnall JT, Krause S. The The Pain Disability Index: Psychometric properties. Pain 1990;40:171-82.

49. Chibnall JT, Tait RC. The Pain Disability Index: Factor structure and normative data. Arch Phys Med Rehabil 1994;75:1082-6.

50. Zigmond AS, Snaith RP. The hospital anxiety and depression scale. Acta Psychiatr Scand 1983:67;361-70.

51. Ware JE, Kosinski M, Keller SD. A 12-item Short-Form Health survey: Construction of scales and preliminary tests of reliability and validity. Med Care 1996;34:220-33.

52. Kieburtz K, Simpson D, Yiannoutsios C, et al; and the AIDs Clinical Trial Group 242 Protocol Team. A randomized trial of amitriptyline and mexiletine in painful neuropathy in HIV infection. Neurology 1998;51:1682-8.

53. Mitchell SW. Injuries of Nerves and Their Consequences. Philadelphia: JB Lippincott \& Co, 1872:270.

54. Butler SF, Fernandez K, Benoit C, et al. Validation of the revised screener and opioid assessment for patients with pain (SOAPP-R). J Pain 2005;9;345-52.

55. Webster LR, Webster RM. Predicting aberrant behaviour in opioidtreated patients: Preliminary validation of the opioid risk tool. Pain Med 2005;6:432-42. 


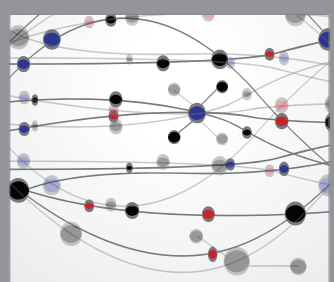

The Scientific World Journal
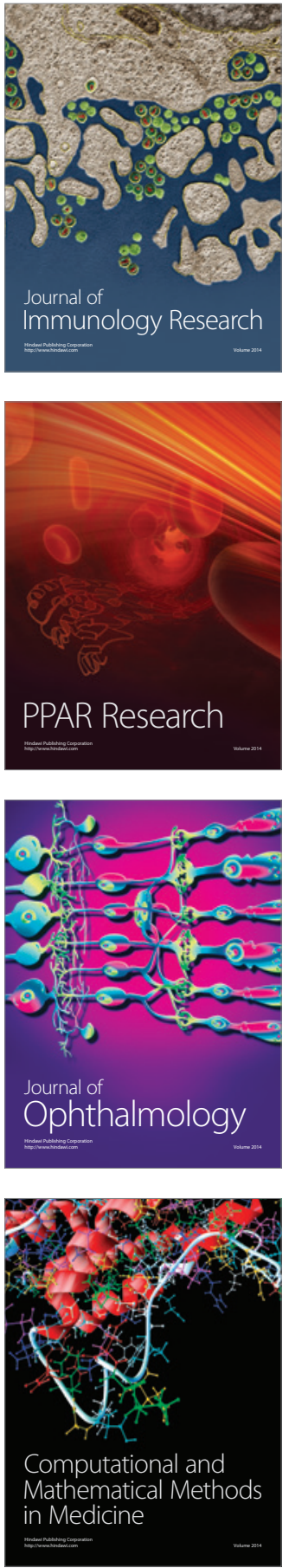

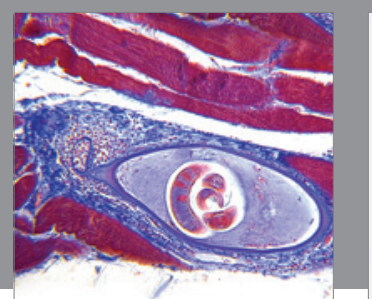

Gastroenterology Research and Practice

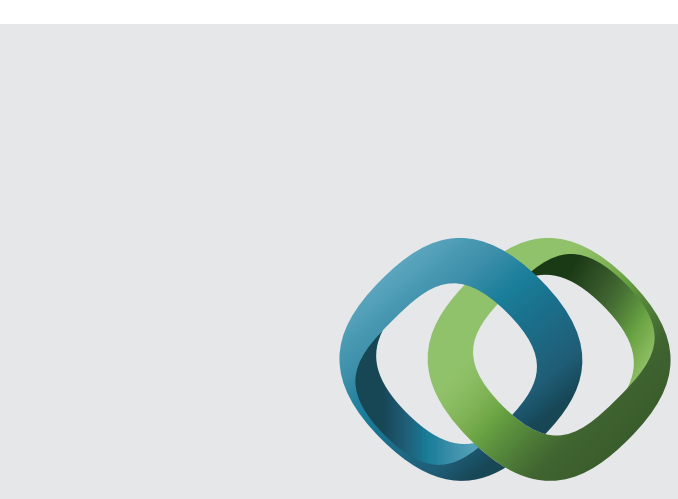

\section{Hindawi}

Submit your manuscripts at

http://www.hindawi.com
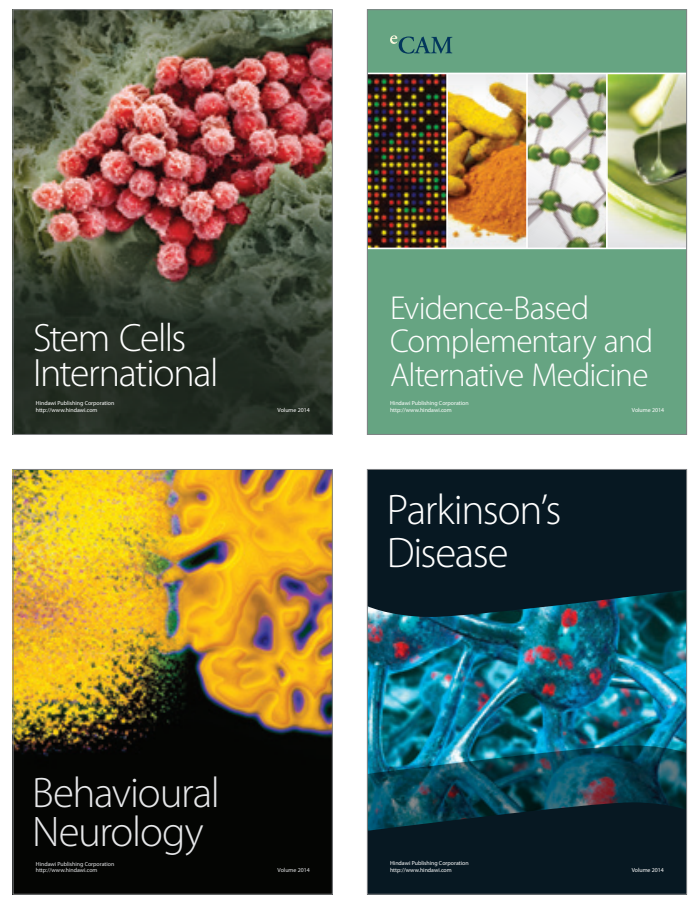
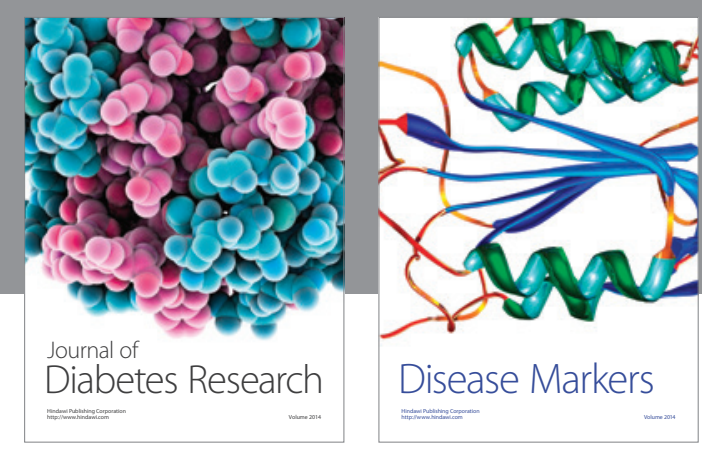

Disease Markers
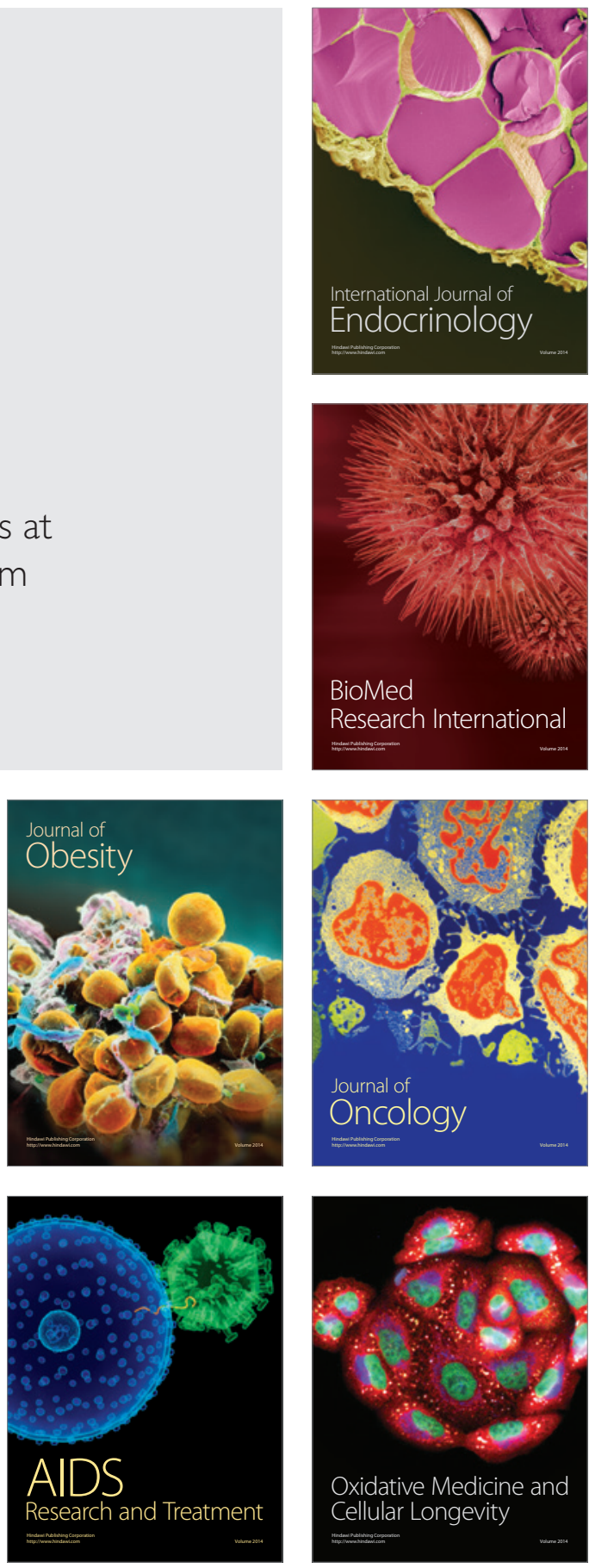